See discussions, stats, and author profiles for this publication at: https://www.researchgate.net/publication/335906546

Employing Finance in Pursuit of the Sustainable Development Goals: The Promise and Perils of Catastrophe Bonds

Article in Academy of Management Discoveries · September 2019

DOI: $10.5465 / \mathrm{amd} .2018 .0137$

CITATIONS

6

3 authors, including:

Emmanuel Kypraios

National University of Ireland, Maynooth

4 PUBLICATIONS 18 CITATIONS

SEE PROFILE
199

Bernard Forgues

emlyon business school

45 PUBLICATIONS 939 CITATIONS

SEE PROFILE

Some of the authors of this publication are also working on these related projects:

Catastrophe Bonds - Fintech View project 


\title{
EMPLOYING FINANCE IN PURSUIT OF THE SUSTAINABLE DEVELOPMENT GOALS: THE PROMISE AND PERILS OF CATASTROPHE BONDS
}

\author{
DROR ETZION ${ }^{1}$ \\ McGill University \\ EMMANUEL KYPRAIOS \\ Maynooth University, School of Business \\ BERNARD FORGUES \\ Emlyon Business School
}

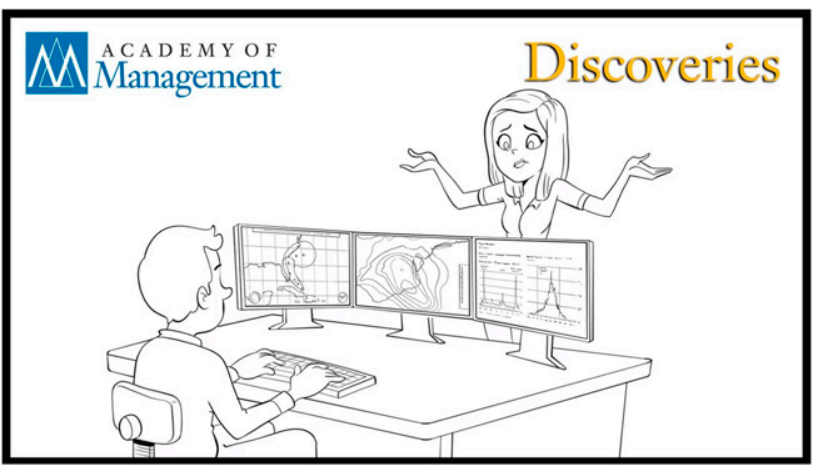

The UN sustainable development goals (SDGs) present a formidable funding challenge. Financial innovation is one way through which resources can be secured, while also providing business opportunities for market actors. The insurance sector, in particular, has been at the forefront of such innovation, developing financial instruments to manage the flooding, fire, and storm risks that characterize an increasingly unstable world. We examine one such financial instrument-the catastrophe bond-which transfers extreme risk from insurers and reinsurers to capital markets. Using a comprehensive database of all catastrophe bonds issued through March 2016, we find that the modeling which underlies catastrophe bonds is not demonstrably better than guesswork at predicting the financial consequences of extreme events. Moreover, secondary data reveal that market actors are under no illusions about the level of precision and accuracy provided by the models. Our analysis suggests that catastrophe bonds do not lend themselves to analysis through conventional sociological theories of financial markets. Drawing on theories of ignorance, we reflect on the social arrangements that sustain financial markets in contexts of extreme uncertainty. We conclude with some cautionary notes for harnessing financial tools in support of the SDGs.

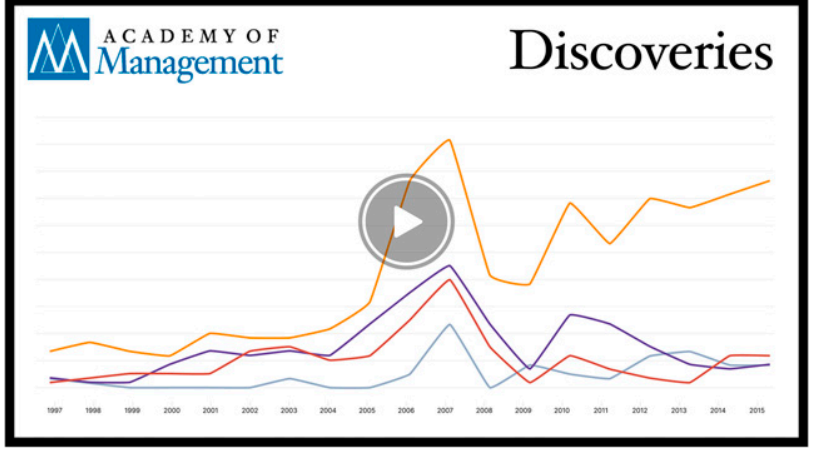

We would like to thank Steve Evans at Artemis, Daniel Beunza, Martin Boyer, Paula Jarzabkowski, Toni Vukadinovic, Jessica Weinkle, and Daniel Wilks; participants of 4S/EASST 2016, ARCS 2016, EGOS 2016, and
OMTF 2016; and our informants in the field. In addition, we are indebted to our editor, Chet Miller, for excellent guidance, and to our anonymous reviewers.

${ }^{1}$ Corresponding author. 
The sustainable development goals (SDGs) are remarkable for their audacity. Their implications for how we construct our lives, our economies, our societies, and our relationship with nature cannot be overstated. Of course, to attain a set of goals so transformative, many systemic changes are required, involving governance, technology, culture, and belief systems. Not least, their implementation requires vast sums of money. The effort required to mitigate environmental harms and reduce social disparities while at the same time adapting to an increasingly unstable planetary system requires an almost unimaginable amount of resources. One report by the United Nations pegs the required annual investment at \$5-7 trillion (UN Conference on Trade and Development, 2014).

Given that pursuit of the SDGs will require investment on a scale unlike any in human history, it is not surprising that they can be construed as a huge opportunity for business: a means to provide society the products and services required to transition to sustainability (Business and Sustainable Development Commission, 2017; DNV GL, UN Global Compact, \& Sustainia, 2018; GRI, UN Global Compact, \& WBCSD, 2015). Indeed, with business an increasingly dominant player in the world order, it is not unreasonable to assume or expect the for-profit sector to harness its problem-solving skills to tackle the SDGs. Of course, harnessing private enterprise to this mission requires a promise of financial viability, if not outright profitability. Managerial concepts such as "shared value" (Porter \& Kramer, 2011) and the "bottom of the pyramid" (Hart \& Christensen, 2002; Prahalad, 2006) epitomize the notion that corporations can and should prosper by better serving the needs of society.

Recognizing the opportunity for private enterprise to make meaningful contributions to the SDGs and the need to mobilize large amounts of capital, a variety of actors are actively devising and implementing new financial tools and models that seek to integrate sustainability and profitability. The use of financial innovation to attain the SDGs is already manifested through micro finance (Yunus, 1999) and mobile phone applications that promote financial inclusivity (Suri, 2017), through the development of "green" and "social impact" bonds to promote private sector investment into public goods (Khalamayzer, 2017; Warner, 2013), and through the development of markets for the preservation of biodiversity, in which dollar values are assigned to the preservation of species and ecosystems (Costello, Gaines, \& Gerber, 2012; Foale, Dyer, \& Kinch, 2016). These forms of innovation are, however, contentious and polarizing. Empirical questions about their effectiveness abound (Bateman \& Chang, 2012; Popper, 2015), as do more fundamental concerns about their normative underpinnings and consequences for how we value and safeguard "priceless" goods such as robust societies and flourishing ecosystems (Ackerman \& Heinzerling, 2004; Knox-Hayes, 2015; Monbiot, 2018; Sandel, 2013). This debate questions whether financial innovation can be trusted to serve the public good. Or, more generally, in which contexts should we rely on innovative financial products to address the difficult and unprecedented challenges of unsustainability?

We explore this question by analyzing a form of financial engineering that has been embraced by the insurance industry in response to the increasing frequency of extreme-and costly - natural disasters such as flooding and forest fires. Traditionally, insurance companies have dealt with extreme risk through reinsurance-essentially insuring themselves with other, larger insurers, who can spread risk among various geographies and peril types (Jarzabkowski, Bednarek, \& Spee, 2015). But, in the last two decades, claims resulting from extreme events increased substantially (see Figure 1), threatening the viability of the insurance industry as a whole. One way in which the industry has addressed this threat is by developing new financial products, with the goal of attracting additional capital and diversifying risk to other markets (Culp, 2006).

One of these products is the catastrophe bond: a financial tool that provides the issuer, usually an insurance or reinsurance company, a payout in case of a catastrophe, such as a hurricane. These bonds, sold to institutional investors, allow insurers to mitigate extreme risk: in case of a catastrophe strong enough to "trigger" the bond, insurers access the investors' capital and distribute it to claimants. Rather than relying on the traditional reinsurance market, catastrophe bonds offer insurers access to capital from financial entities such as pensions and hedge funds, who often seek to diversify their portfolio risk through investments that are uncorrelated with the broader financial market. Like other forms of financial innovation related to the SDGs, catastrophe bonds garner support from a number of parties-not only from financial actors such as investors, insurance and reinsurance companies, and the World Bank (Harding, 2014) but also from regulators that are otherwise insurers of last resort when catastrophe strikes (Association of British Insurers, 2005; Dickson, 2013), and environmental activists who constantly seek novel ways to promote sustainability (Cleetus, 2013; Linnenluecke, Smith, \& McKnight, 2016; UNEP, 2013).

Notwithstanding this support from a diverse set of stakeholders, the viability of using economic and financial tools for coping and adapting to greater instability in a rapidly warming world warrants scrutiny. An assessment of the effectiveness of catastrophe bonds requires a thorough exploration of the modeling work that underpins them. We proceed by examining these models via the two primary theoretical lenses through which financial markets have been conceptualized-the camera and the engine. Theorizing markets as cameras 
FIGURE 1

Worldwide Catastrophe Losses (\$ billion)

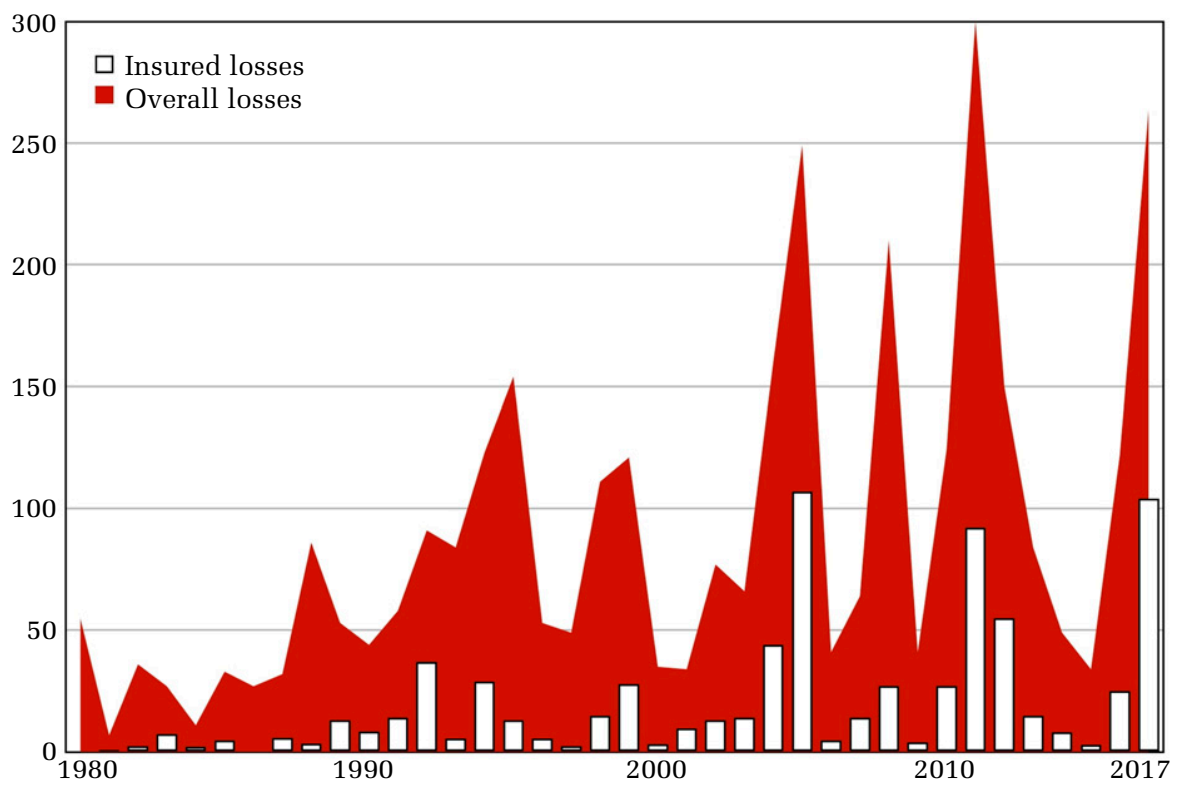

Note: Data source: MunichRe, https://natcatservice.munichre.com/s/XXzrK.

equates them to passive recorders of value; theorizing markets as engines assigns them greater agency and acknowledges their power to themselves creating change in the world (MacKenzie, 2006). We find neither of these lenses satisfactory for understanding valuations in the catastrophe bond market. Specifically, our analyses suggest that catastrophe models are not accurate: they systematically overestimate risk and do not predict better than guesswork. Thus, they are not cameras. At the same time, unlike derivative pricing models, e.g., they are not logically derived from economic frameworks and do not appear to drive market behavior and perceptions of value toward theoretically informed levels. They are, therefore, not engines.

Our data and analyses lead us to suggest that the accuracy of catastrophe models is indeterminate. We highlight this indeterminacy by making several sequential assertions. First, we demonstrate how uncertainty is ingrained in the risk models that underlie catastrophe bonds and show that this uncertainty is unavoidably large. Next, we establish that the cumulative predictive power of all catastrophe bonds over the past two decades has been less accurate than would have been generated by guesswork. We then show that the yields that catastrophe bonds provide are

\section{Author's voice:}

What is the social relevance of your research? determined primarily not by the odds of their being triggered but rather by exogenous factors, namely, macroeconomic conditions, liquidity in the insurance industry, and investor demand. Together, these findings suggest that the financial value of catastrophe bonds is only loosely associated with the catastrophe coverage they provide. We also find that to date, on aggregate, catastrophe bonds have been consistently profitable for the financial entities that have invested in them. Nonetheless, the models are not or-more accurately—cannot be proven wrong or biased in any strict sense of the word. Given this conclusion, we speculate about the social arrangements that might maintain and support financial instruments that are highly uncertain and whose value is largely unknowable, and discuss the implications of using these tools to promote the sustainable development goals.

\section{RISK, INSURANCE, AND THE SUSTAINABLE DEVELOPMENT GOALS}

Global economic elites often frame sustainability as a risk management problem and emphasize that comprehending and addressing risk is eminently prudent. For example, Michael Bloomberg, Former Treasury Secretary Hank Paulson, and venture capitalist Tom Steyer established and lead a coalition called the "Risky Business Project," which contends that "the economic risks from unmitigated climate change to American businesses and long-term investors are large and unacceptable” (Risky Business Project, 2016: 88). The 
World Economic Forum has long embraced the framing of sustainability through risk. In early 2019, it issued its 14th annual Global Risks Report in the run-up to the 2019 Davos meeting. The top three risks identified in the report are environmental. In order, they are extreme weather events, failure of climate change mitigation and adaptation, and natural disasters (World Economic Forum, 2019). Relatedly, 10 of the 17 SDGs have been identified as salient to disaster risk reduction (UN Office for Disaster Risk Reduction, 2015).

The loss of life and property from natural catastrophes is of course critical. Indeed, the disruption caused by such events is so severe that one of the largest sectors in the global economy-the insurance industryspecializes in managing these risks, and in doing so provides an important service to society. According to Michael Bloomberg, who serves as UN Special Envoy for Climate Action, "the more insurers understand climate risks facing the economy, the more they can make prudent decisions in managing risk and serving their clients, and the more efficient and stable our markets will become" (UNEP FI, 2018). The global insurance sector has constructively engaged with the United Nations to develop Principles for Sustainable Insurance (https://www.unepfi.org/psi/the-principles/). Through these principles, many of the world's largest insurers have committed to work with governments, regulators, and other stakeholders to develop insurance solutions in line with the SDGs (Jaeggi, 2015). The unit within the UN that manages the partnership with the insurance sector is the UN Environment Programme - Finance Initiative (UNEP FI), a partnership with more than 230 financial institutions dedicated to promoting "sustainable finance" (https://www.unepfi.org/about/structure/).

Devising insurance solutions for a destabilizing world is a challenging endeavor, far removed from the ubiquitous retail products that constitute part of our everyday lives. The "bread and butter" services provided by insurance companies allow people and organizations to safeguard themselves against unfortunate yet limited events such as property loss and personal injury. Usually, events like these occur sporadically and in a randomly (temporally and geographically) distributed fashion. For insurance to be viable, an insurance company insures a large number of people, whose risk profiles are essentially uncorrelated (Denuit, Dhaene, Goovaerts, \& Kaas, 2015).

Certain types of events are generally quite predictable, and claims are, in fact, unlikely to be correlated. A good example is life insurance. Life expectancy statistics are used to develop actuarial tables, based on very large sample sizes, yielding high statistical power. Moreover, the death of one individual will, in most cases, be statistically independent of the deaths of other individuals, so that the insurance payouts following deaths are randomly dispersed. Predictability and low correlation thus reduce risk when large numbers of individuals are pooled together via insurance. As such, the business model of successful insurance is based on an income stream that originates with client premiums. Because of the law of large numbers, the likelihood of claims (expenditures) rising beyond income is small, albeit not zero.

Not all types of insurance, however, have these convenient statistical characteristics. For example, the population size might be small, as in the case of maritime insurance-the insurance of shipping vessels-a class of insurance that has been portrayed as akin to voodoo, in that it harnesses tacit knowledge shared within closed epistemic communities (Jarzabkowski et al., 2015). Extreme weather and natural disaster insurance are even more challenging. Forest fires and weather-induced flooding can affect an entire region, creating a large number of claimants at the same time, thereby violating statistical independence. Because insurers tend to be rather nondiversified in terms of the risk coverage they offer and the geography in which they operate, a large event such as a flood or a fire can lead to a spike in payouts, leading to insolvency (Gründl, Dong, \& Gal, 2017).

\section{Insuring Rare Events}

\author{
"[New York] has a 100-year flood every two \\ years now." \\ (Gov. Andrew Cuomo, in the aftermath of \\ Hurricane Sandy, as cited in UPI, 2012).
}

As Governor Cuomo's pronouncement suggests, when it comes to rare events, our intellectual capacities may be challenged. Gov. Cuomo expressed this sentiment after witnessing the havoc of Hurricane Sandy in his state. Sandy hit New York in October 2012, 14 months after Hurricane Irene-itself at the time the seventh costliest hurricane in the U.S. history-and left in its wake extensive damage, most notably to New York City. At face value, Gov. Cuomo's statement seems to deride the validity of risk models that claim that extreme weather events are rare, if they take place in rapid succession. Yet, at the same time, there is nothing inherently implausible about the statement either and not one that risk modelers would dispute. Just as a gambler can get a lucky streak at the roulette table, so too can several infrequent weather events occur in close succession without discrediting the validity of the statistical model that predicts them.

Gov. Cuomo, one might assume, is not only interested in the epistemological ruminations that arise from contemplating extreme weather events but also in their costs. These concerns are even more acute for insurance companies the world over, particularly as the 
climate changes, and "peak perils" increase (Willis Capital Markets \& Advisory, 2015). Over the past years, insurers have understood that adaptation to increasing environmental instability is a cardinal concern for their long-term survival. Put simply, insurance companies can remain viable only to the extent that they can accurately assess and price the risk they assume. As climate change intensifies, more large-scale events such as droughts, floods, and hurricanes occur (Coumou \& Rahmstorf, 2012). These events also become more intense, creating greater mortality and property damages, which, if insured, raise payouts. The heightened intensity of extreme weather events makes them historically unique, with few or no historical precedents. Consequently, the expected monetary consequences of the damage they are likely to cause is difficult to predict (Pielke Jr., Gratz, Landsea, Collins, Saunders, \& Musulin, 2008). This is the crux of the problem facing insurers that seek to fulfill the principles of sustainable investment and contribute to addressing the SDGs.

\section{RESEARCH SETTING: CATASTROPHE BONDS}

To mitigate extreme risk, insurance companies have traditionally insured themselves with companies known as reinsurers. Reinsurers spread risk by providing greater diversification than insurers can generate internally. They do so by covering insurers with different domains of coverage and in different geographies. The appeal of reinsuring is to pass on the risk of a particularly extreme event to another entity better structured to accommodate it.

Another tool that insurers can use to manage rare risks is catastrophe bonds. Catastrophe bonds offer the same functionality of risk transfer as reinsurance, with one major difference: they transfer extreme risk not to reinsurers but to other financial actors instead. Catastrophe bonds were devised in the mid-1990s, in the aftermath of Hurricane Andrew-at that time, the most costly hurricane in the U.S. history, totaling \$15 billion-and the Northridge Earthquake, events of such magnitude that the insurance industry began to look for complementary mechanisms to manage risks. Insurers recognized that catastrophic events such as these could make reinsurance exorbitantly expensive, and that spreading risk even more widely, to financial entities outside the insurance sector, could lower costs and attract more capital. In effect, catastrophe bonds were devised to spread insurance risk to qualified investors outside the insurance sector.

A catastrophe bond is thus a financial tool that provides the issuer (most frequently an insurer or a reinsurer) protection in case of a major catastrophe, usually an extreme natural catastrophe such as a hurricane or an earthquake. Catastrophe bonds are very specific in terms of the coverage they provide, and a prospectus typically runs to several hundred pages. The bonds can be triggered in several ways. For instance, one could be triggered if an earthquake of a minimum magnitude of 7.5 occurred in a delimited region on the U.S. West Coast within the next three years. Or it could be triggered only after the payouts by the insurer or reinsurer (the "cedent" or "sponsor" of the bond) following the catastrophe exceeds a certain predefined dollar threshold (for a thorough overview, see Cummins \& Weiss, 2009). Catastrophe bond coverage typically extends to tens or hundreds of millions of dollars, very rarely exceeding $\$ 500$ million. Like conventional reinsurance agreements, catastrophe bonds provide coverage for a "layer," or "tranche" of risk, e.g., to cover the losses incurred by the cedent after the first $\$ 2$ billion in payouts, up until $\$ 2.3$ billion in payouts, in such manner diversifying the sources of revenue to be tapped following an extreme event. Therefore, even when disaster strikes in a region covered by a bond, it may not be triggered.

From an investors' perspective, catastrophe bonds are attractive because they present a unique investment opportunity that is uncorrelated to financial markets. They are thus a useful asset class for diversifying risk in an investor's portfolio. This characteristic makes catastrophe bonds especially appealing to institutional investors, by providing not only attractive returns but also a way of addressing the most pernicious of financial risks: global systemic risk (Centeno, Nag, Patterson, Shaver, \& Windawi, 2015) or the risk that originates from the tight interlinkages between all sectors of the world economy. Put simply, it is hard to find an investment vehicle less dependent on the health of global financial markets than an earthquake. Indeed, whereas virtually the entire financial system collapsed in 2008, the Swiss Re Global Cat Bond Performance Index ${ }^{2}$ actually rose by 2.5 percent (Johnson, 2013). Catastrophe bonds in the United States returned 22 percent between 2012 and 2014, roughly equivalent to the returns from corporate junk bonds, during a period that included damage caused by Hurricane Sandy (Chen, 2014). These rates of return have drawn in many new investors over the past decade, ranging from pension funds to sovereign funds to hedge funds. The total catastrophe bonds on-risk reached $\$ 33$ billion as of year-end

\footnotetext{
${ }^{2}$ The index is a market value-weighted basket of natural catastrophe bonds tracked by reinsurer Swiss Re's Capital Markets division. Launched in 2007, it is today the point of reference for cat bond sector returns. The index tracks the performance of all catastrophe bonds issued, denominated in any currency, unrated or rated. See https://www.swissre. com/Library/swiss-re-cat-bond-indices-methodology.html for more details.
} 
2017 , roughly 6 percent of the $\$ 600$ billion global reinsurance market (Artemis, 2018).

Catastrophe bonds are customarily structured as private placements (Boyer \& Dupont-Courtade, 2015), meaning that investors like pension funds and sovereign wealth funds are approached privately, by means of a roadshow, where the issuer, possibly accompanied by the catastrophe modeling agent (see in the following text), introduces the bond, answers questions, and gauges potential investors' interest in the offering. By the end of the roadshow, final details have been worked out, a price has been finalized, and the bond has been sold to qualified investors (Lalonde \& Karsenti, 2008). Once a deal is finalized, the principal is placed in a special purpose vehicle, or SPV, a legal entity set up solely for managing the money raised by the bond (see Figure 2). Before the 2008 financial crisis, SPVs often invested the principal in various channels, but following four catastrophe bond defaults that ensued from the Lehman Brothers bankruptcy, SPVs now have much stricter collateral arrangements, keeping their holdings in U.S. Treasury Bills or similar low-risk investments. If the covered natural catastrophe occurs during the risk period, part or all of the money from the SPV is transferred to the cedent to cover their insurance losses. Otherwise, at maturity, the principal is returned to the investor. Throughout the duration of the bond, the investor receives coupon payments as specified in the prospectus. The cash flow for the coupon payments originates from premiums of insured clients, collected by the cedent.

In effect, catastrophe bonds have a similar structure to other "quasi-bonds" available to institutional investors, such as mortgage-backed securities and collateralized debt obligations (Vinokurova, 2012). This structure is appealing to investors and issuers because it accommodates lower regulatory capital requirements, and thus can be highly leveraged. Like other complex quasi-bonds, catastrophe bond trading takes place only between specialized financial experts who pore over lengthy prospectuses and intricate computer models before striking a deal.

\section{Catastrophe Models}

As our lengthy description highlights, catastrophe bonds are intricately constructed financial arrangements. And yet, they are often perceived as rather straightforward. A broker interviewed by Hintze (2013) explained: "When I talk to people involved in the commercial mortgage-backed securities market, they practically laugh at how simple cat bonds are." However, they are perceived to be simple because their logic is straightforward, rather than because risk can accurately be assessed. Indeed, others disagree that the products are simple and shun catastrophe bond offerings because they are described in prospectuses that are "telephone book-thick" (Stovin-Bradford, 2015). At the heart of these telephone book-thick documents lie catastrophe risk models.

Because natural catastrophes are rare and unpredictable, actuarial tables are of limited value for divining the risk of extreme events (Cabantous \& DupontCourtade, 2015). Instead, quantification of risk is performed through a process known as catastrophe risk modeling. These models are conceptually distinct from actuarial tables because they are not based on large statistical samples. Instead, catastrophe models use mathematical formulas and stylized simplifications of natural phenomena to run simulations that mimic realworld scenarios. The models are empirically calibrated, yet the amount of historical data that can be used is limited by the number of rare events recorded.

Three specialized companies-RMS, CoreLogic (formerly EQECAT), and AIR-provide most catastrophe risk models in use in the insurance industry (Grossi \& Kunreuther, 2005). These models have three components (Clark, 2002). First, a hazard model harnesses expertise in meteorology, climatology, oceanography, geophysics, and other natural sciences to predict the incidence and intensity of catastrophic events. Then, damage models use techniques from civil engineering to predict how buildings and infrastructure will fare in extreme conditions. Finally, loss models are economic models that forecast the cost of repairing damages, as well as indirect losses such as business interruption and relocation costs. Catastrophe risk models run these components sequentially and generate thousands of simulated scenarios (Muir-Wood, 2016). Models are validated using historical data by assessing whether model outputs for events similar to those in the historical record in fact yield damage and loss predictions that correspond to those incurred in actual events (Pielke Jr., Landsea, Musulin, \& Downton, 1999). Each of these steps is consummately professional and harnesses state-of-the art knowledge. Indeed, all of the modeling companies have dozens of PhDs on payroll, across an array of disciplines. Catastrophe models are widely available and are used by both buyers and sellers. Consequently, the market for catastrophe risk does not suffer from endemic information asymmetries.

\section{DATA}

We compiled a comprehensive list of all catastrophe bonds issued from the inception of the catastrophe bond market in December 1996, until March 2016. Publicly available data on catastrophe bonds are scarce, and most transactions take place over the counter rather than via exchanges. Therefore, we obtained proprietary comprehensive data synthesized in the Artemis Deal 
FIGURE 2

A Prototypical Catastrophe Bond

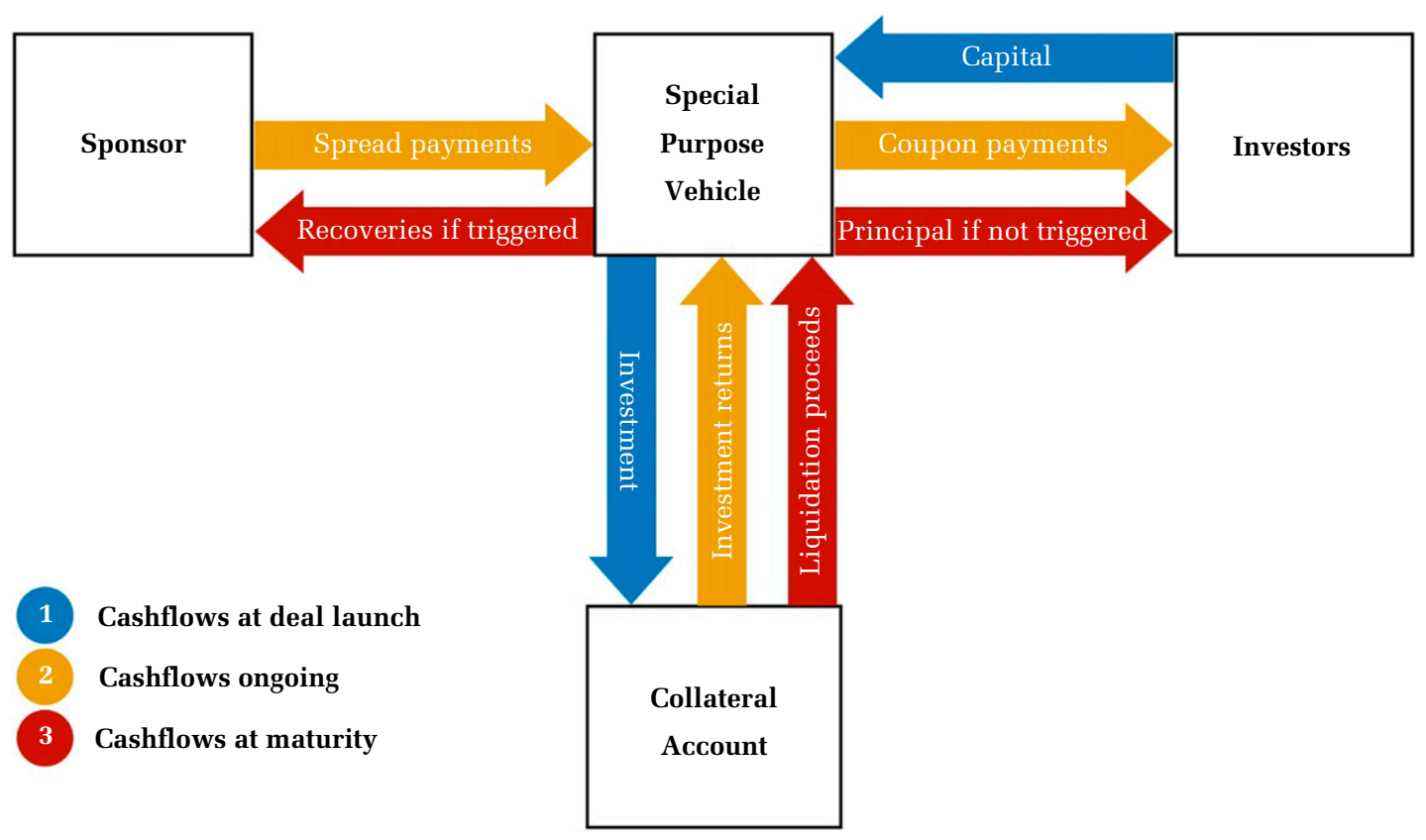

Directory (www.artemis.bm), similar to the datasets used by insurance researchers examining catastrophe bonds (e.g., Braun, 2016; Gürtler, Hibbeln, \& Winkelvos, 2016). Like mortgage-backed securities and other financial instruments, catastrophe bonds are often structured in tranches, which provide several layers of risk and reward within the same deal. In total, our dataset comprised 612 tranches within 383 deals.

For each tranche, we obtained the following primary information: the name of the cedent (sponsor), its size (in millions of US dollars), its date of issue, and its duration. In particular, we noted the probabilities of attachment (the likelihood for a bond to be triggered, as specified in the prospectus) and exhaustion (the likelihood for a bond's principal to be transferred in its entirety to the cedent, again as specified in the prospectus). Perhaps, the most important metric in the catastrophe bond market is the expected loss, defined as "the average loss that investors can expect to incur over the course of a period (usually one year) divided by the principal amount invested" (Willis Capital Markets \& Advisory, 2015). We also calculated the spread for each tranche, specifically the difference between the coupon and the risk-free interest rate in the form of the U.S. Treasury spot curve.

To put catastrophe bond coupons in economic context, we followed the recent literature in insurance economics (Braun, 2016) and captured the influence of the corporate bond market on catastrophe bonds-and particularly the effects of speculative grade bonds rated similarly to catastrophe bonds-via the Bank of America Merrill Lynch U.S. High Yield BB Option-
Adjusted Spread. This measure is calculated as the difference between a yield index for the BB rating category and the Treasury spot curve. ${ }^{3}$

Major natural disasters greatly affect insurance markets. Born and Viscusi (2006) called such events "blockbuster catastrophes" and showed that they have direct economic consequences in terms of subsequent premiums and willingness to take on risk. We thus collected information on the 10 "default events" since 1998-the events that caused capital losses to catastrophe bond investors. For each default event, we noted the cause, the catastrophe bond that was primarily affected, the capital at risk, the expected loss, and the percentage of loss of capital invested by catastrophe bond investors. ${ }^{4}$

Finally, we obtained catastrophe model documentation for the state of Florida (USA), the region that has been covered most extensively via catastrophe bonds over the years. Florida oversees the

${ }^{3}$ Rating agencies typically rate catastrophe bonds at speculative ("junk bond”) grade. Standard and Poor's (2013: 16) provides the following rationale: "Natural catastrophes can occur at any moment and depending on the peril, without warning, resulting in a default or ratings downgrade. Therefore, based on our credit stability criteria ... we typically cap the nat-cat risk factor and, thus, the rating on a single-event natural peril catastrophe bond at 'bb+' and 'BB+', respectively."

${ }^{4}$ As noted earlier, not all natural catastrophes result in losses to bondholders. This is because some areas are underinsured or because the insured losses are covered directly by the risk held by the insurer and the reinsurer. 
accuracy and reliability of catastrophe models used in the state by stipulating that catastrophe model vendors submit detailed documentation on how they generated their models and model output to Florida's Commission on Hurricane Loss Projection Methodology (Weinkle \& Pielke Jr., 2017). These documents, spanning hundreds of pages each, were generated annually by the modeling firms RMS, CoreLogic, and AIR Worldwide, and by the International Hurricane Research Center at Florida International University. We downloaded them from Florida's State Board of Administration's website. ${ }^{5}$

\section{ANALYSIS}

Sociologists of finance study the role of financial models in shaping markets and market behavior (Carruthers \& Kim, 2011). A point of emphasis is that financial models may not only capture and reflect aggregate market activity but can also shape transactions and become performative. In his highly influential book, MacKenzie (2006) captures this insight by using two metaphors. In the camera metaphor, models are merely devices that help understand the reality of what transpires in markets. They are simplified mathematical representations of market processes and produce knowledge. Just like the machineries of knowing studied by Knorr-Cetina (1999: 286), they play a part in goals of "anticipation, identification, and calculation." In the engine metaphor, by contrast, the theorization that underlies models also shapes what happens in markets. This striking role reversal draws on performativity theory (Austin, 1976; Marti \& Gond, 2018) and provides a conceptual foundation that allows analysts to understand and describe processes through which models of markets become self-fulfilling (MacKenzie \& Millo, 2003). According to both metaphors, models correspond with reality, either because they faithfully record market behavior or because they encourage market actors to behave in accordance with theory.

Our analysis proceeds by examining whether either of the two metaphors is applicable to catastrophe models. We start by assessing their precision and historical accuracy, thus testing whether they function as cameras. We then assess whether the engine metaphor is apt, by examining how catastrophe models are revised and what effects these revisions have on markets.

\section{Are Catastrophe Bonds Cameras?}

To assess whether catastrophe bonds can be understood as cameras that capture risk, we examine two

\footnotetext{
${ }^{5}$ https://www.sbafla.com/method/ModelerSubmissions/ PreviousYearsModelSubmissions.aspx
}

distinct yet related questions. First, we explore whether they are precise. Do they provide forecasts with a level of specificity that is useful on decisionmaking? Second, we explore whether they are accurate. Do the forecasts they provide correspond with the historical record? Put differently, the question about precision deals with confidence intervals, and the question about accuracy deals with point estimates.

To analyze precision, we use data from the Florida Commission on Hurricane Loss Projection. In 2013, the commission provided modelers a set of parameters defining a hypothetical hurricane and asked to see the modeling results. Figure 3 is an example of a scenario used in risk models, revealing their linear design. The panel on the left focuses on meteorological risk and predicts the occurrence, intensity, and movement of hurricanes. The panel on the right focuses on the physical damages caused by the hurricane and rebuilding costs. Each of the boxes in the flowchart depicts rather elaborate submodels. ${ }^{6}$ For example, the submodel for hurricane severity uses a Poisson distribution to calculate storm frequency, a Gaussian distribution to calculate inland filling rate (a measure of storm decay), a lognormal distribution for maximum wind speed, a truncated lognormal distribution for calculating the radius of maximum wind speeds, and gamma distributions for additional wind parameters. The submodel for incremental damage factors assumes proportions of different types of structures (wood frame, masonry, mobile home, and concrete), places them at the centroid of each zip code in the state, and examines the impact of wind speed on their integrity, whereas ignoring appurtenance structures and contents. These and other simplifications throughout the modeling process make calculations tractable.

Notably, confidence intervals are presented only for very few model components. One component is wind speed, as portrayed and explained in Figure 4. It reveals a confidence interval of roughly \pm 50 percent as regards the effect of just one factor, wind speed, on financial losses. Even this limited information about confidence intervals is revelatory, however. As emphasized earlier (particularly in Figure 3), catastrophe models are sequential. Consequently, confidence intervals that are output from one submodel generate larger confidence intervals in subsequent phases. This is because mathematically confidence intervals propagate through subsequent calculations. In other words, if there is a big error term in one variable in a formula, then it is mathematically straightforward to demonstrate that the outcome has

${ }^{6}$ Detailed descriptions of the other sub-models are available in the files posted on the Florida's State Board of Administration website. 
FIGURE 3

Flowchart of Scenario Generation
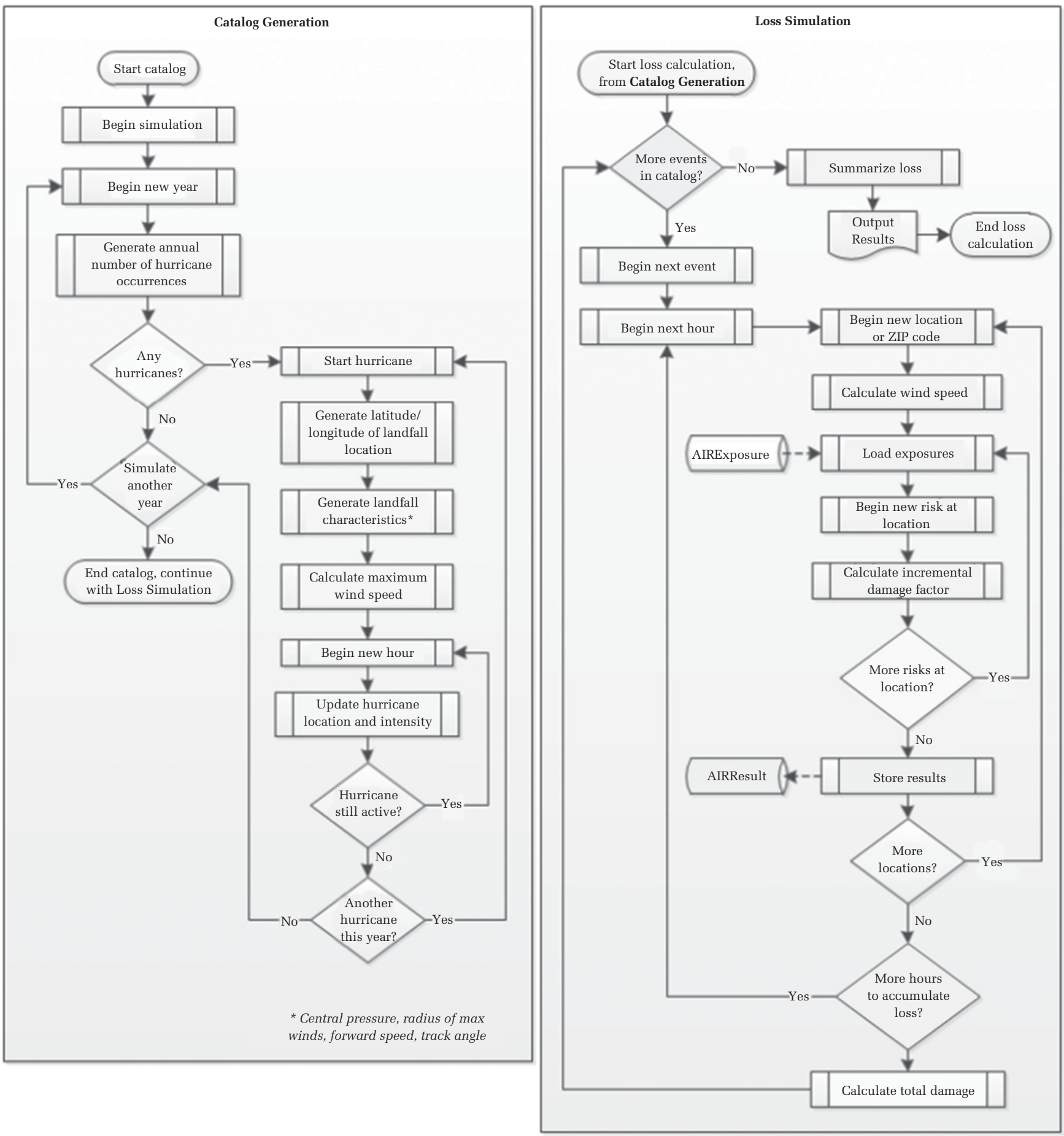

Note: Source: AIR Worldwide (2017). Copyright @ 2017 AIR Worldwide. All rights reserved. Reprinted with permission.

to have at least the same size of error (Clifford, 1973; Hoffman \& Hammonds, 1994). And indeed Florida documentation reveals large confidence intervals in the projected costs, in some cases more than a factor of 10 (Table 1). In sum, although catastrophe models generate a point estimate for catastrophe losses, these estimates are accompanied by error bars that can be an order of magnitude larger. Catastrophe models are imprecise. If we compare them with cameras, then the image they provide is very fuzzy. 
FIGURE 4

Projected Effect of Wind Speed on Financial Losses

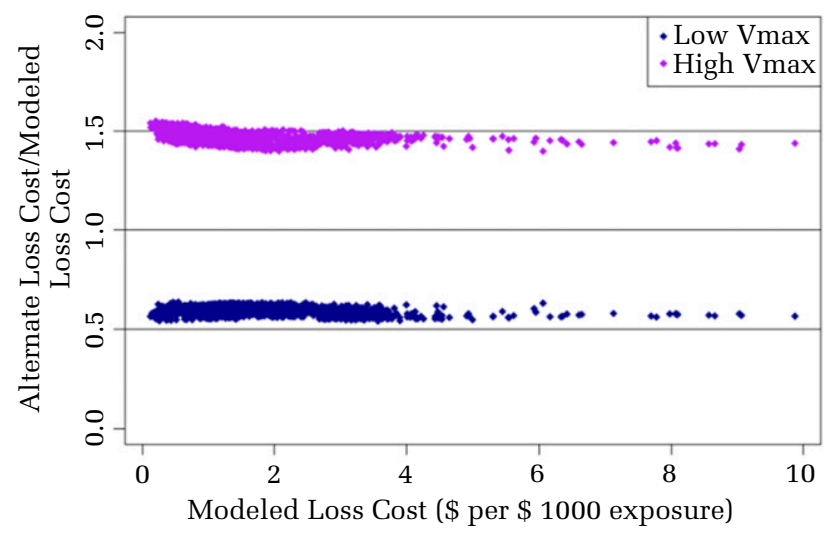

Note: Source: Risk Management Solutions (2013). Copyright $\odot$ 2013 Risk Management Solutions, Inc. All rights reserved. Reprinted with permission. As explained in the accompanying text, "each point represents the average annual loss per $\$ 1,000$ of exposure for a ZIP Code. $V_{\max }$ is set to "low" and "high" values to obtain alternate loss costs, which are compared with the original losses. The 5 percent and 95 percent confidence bounds on the $V_{\max }$ CDF [sic - Cumulative Distribution Function] are used to set the "low" and "high" limits ... The blue (purple) points show the ratio of alternate to original loss costs when $\mathrm{V}_{\max }$ is set to "low" ("high") versus the loss cost resulting from the original modeled $V_{\text {max. }}$ "

How accurate are catastrophe models? The primary output of catastrophe models, as regards catastrophe bond pricing, is known as the expected loss, defined as the average loss that investors can expect to incur over the course of a period (usually one year) divided by the principal amount invested. A more intuitive metric is the probability of attachment, defined as the likelihood that a catastrophe bond will suffer some losses over the course of a one-year period (Willis Capital Markets \& Advisory, 2015). Both are listed in the prospectuses for catastrophe bonds and are given as a percentage.

Of course, to the extent that these percentages are not 0 or 100 , they can never be inaccurate. This characteristic is true of all forecasts and encountered most frequently in the quotidian weather forecast. A typical meteorological forecast will predict, e.g., a 30 percent chance of rain and of course will be correct, regardless of whether it rains or not-a binary outcome-on that specific day. It is only when aggregating sequences of predictions that forecast accuracy can be assessed. The method for doing so is intuitive. Continuing with the rain example, over a long enough period of time, if we tabulate the number of days in which a forecaster predicted a 30 percent chance of rain, then perfect accuracy implies that the percentage of days in which it did in fact rain should be precisely 30 percent.

To date, more than 600 catastrophe tranches have been issued, allowing us to assess forecast accuracy of this statistical population. Figure 5 is a histogram of probabilities of attachment, revealing that the majority have probabilities of attachment less than 5 percent.

Of these bonds, a mere 10 have been triggered (see Table 2). Although this might be surprising at the first glance, given that catastrophe bonds cover regions with high likelihood of catastrophe, it is worth remembering that the bonds are triggered only when losses are large. For example, only two of the nine outstanding catastrophe bonds covering the Gulf of Mexico triggered because of hurricane Katrina in 2005. And in fact, 4 of the 10 bonds listed in Table 2 were triggered because of insolvency of the special purpose vehicle run by Lehman Brothers as a consequence of the global financial crisis, ${ }^{7}$ leaving only 6 bonds that were triggered as a result of natural catastrophe.

To access the interactive data visualization for Table 2, click here.

Figure 6 presents a reliability diagram, or attributes diagram (Hsu \& Murphy, 1986), in which the observed frequency of triggers is plotted against the forecast probability. In this graph, we chose to divide the range of forecast probabilities into bins of 1 percent. The diagonal on the plot constitutes a reference line of perfect forecasting accuracy. This line represents an ideal situation in which the percentage of catastrophes forecasted to occur at a certain probability is observed at precisely the number of times equivalent to that percentage. The farther the actual observations (the points on the graph) are from this line, the less reliable the forecasts that were made. The figure reveals that the observed catastrophe frequencies were somewhat lower than predictions, particularly for forecasts that predicted a high probability of a catastrophe. In other words, catastrophe models overestimated the probability that catastrophes would occur, particularly catastrophes that were modeled as riskier.

An established method for assessing forecast accuracy was developed by Brier (1950), and is known as the Brier score, defined as:

$$
\mathrm{BS}=\frac{1}{N} \sum_{t=1}^{N}\left(f_{t}-o_{t}\right)^{2},
$$

where $f_{t}$ is the probability that was forecast, $o_{t}$ is the actual observed outcome ( 0 if it does not occur and 1 if it does), and $N$ is the number of forecasting instances. In essence, the Brier score is simply the mean squared

\footnotetext{
${ }^{7}$ A subsidiary of the investment bank, Lehman Brothers Special Financing, acted as total-return swap counterparty for a number of transactions, which subsequently defaulted because of their inability to maintain interest payments and return full principal after Lehman failed.
} 
TABLE 1

Uncertainty Intervals in Loss Levels

\begin{tabular}{rrr}
\hline Return Period (Years) & Estimated Loss Level & Uncertainty Interval \\
\hline Top event & $246,290,375,349$ & $166,220,771,249-337,369,800,696$ \\
1,000 & $123,226,778,794$ & $71,606,691,253-186,893,514,103$ \\
500 & $97,196,173,350$ & $52,207,134,352-152,777,484,797$ \\
250 & $72,118,998,880$ & $35,453,172,114-118,691,917,674$ \\
100 & $44,017,607,833$ & $25,371,585,109-66,843,235,918$ \\
50 & $29,055,466,367$ & $18,408,036,649-41,702,410,720$ \\
20 & $15,835,593,938$ & $5,466,777,037-30,539,755,654$ \\
10 & $8,773,265,608$ & $3,733,685,919-15,521,932,066$ \\
5 & $3,548,629,960$ & $621,591,027-8,445,173,693$
\end{tabular}

Source: Risk Management Solutions (2008). Note the magnitude of the uncertainty intervals in larger and rarer events. For more frequent and less damaging events, the magnitude of the uncertainty is smaller, but the ratio between the high end of the uncertainty interval and the low end is proportionately larger.

error of the forecast (Winkler, 1996). The Brier score ranges from 0 to 1 , with 0 being a perfect score. For our dataset, the Brier score is 0.01, which at the first glance suggests very good predictive power. However, because of the way it is constructed, the Brier score tends to yield a good score when applied to rare events, such as catastrophes (Winkler, 1994).

One solution to remedy this bias is the Brier skill score, derived from the Brier score (Bradley, Schwartz, \& Hashino, 2008; Wilks, 2006). Like the Brier score, the Brier skill score too originates in meteorological forecasting. It assesses the quality of prediction as compared with a constant base rate, usually climatology.
Assume, e.g., a place in which precisely half the days each year, and every year, are rainy. In this place, the climatology base rate for rain is 50 percent. A forecaster could simply predict a 50 percent chance of rain in each day and obtain a reasonably good Brier score, but this forecaster does not provide any meteorological expertise, or "resolution" (Murphy, 1973), and does not attempt to distinguish one day from the other. The Brier skill score assesses the quality of meteorological skill as compared with the climatological base rate, rewarding forecasters that attempt to make sharper, or more meaningful, predictions than climatology. Its formula is as follows:

FIGURE 5

Distribution of Probabilities of Attachment in the Dataset

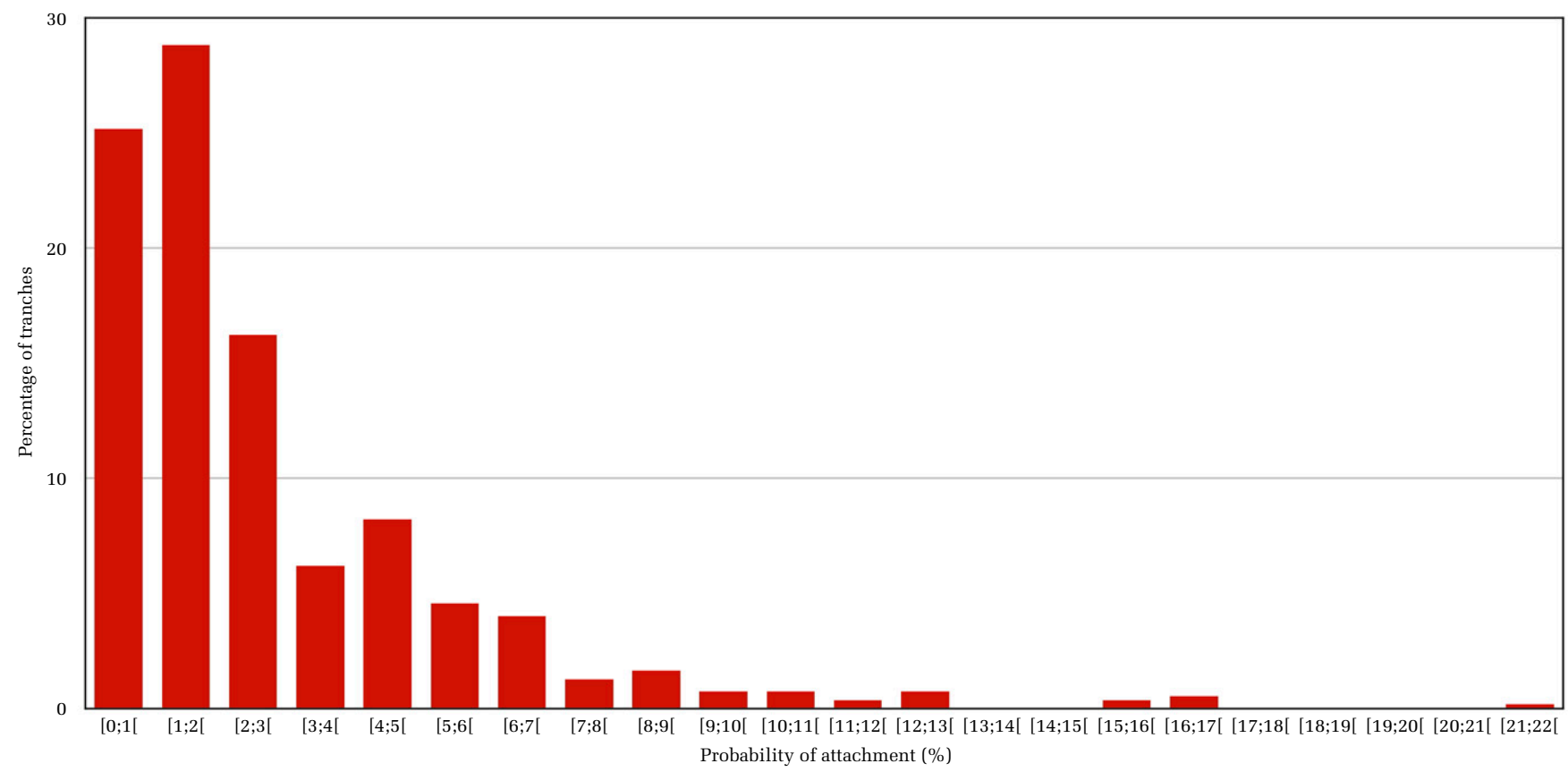

Note: Notation of the $X$-axis: [a; $\mathrm{b}[$ implies a bin that contains all bonds with a probability of attachment equal to or greater than a and less than $b$. 


$$
\mathrm{BSS}=1-\frac{\mathrm{BS}}{\mathrm{BS}_{\text {reference }}},
$$

where $\mathrm{BS}_{\text {reference }}$ is the Brier score attained via consistently forecasting the climatological baseline. Brier skill scores range from negative infinity to 1 , the latter being a perfect score. A skill score of 0 implies no meteorological skill, equivalent to selecting the climatological base rate for each individual forecast.

Using our database, we can easily calculate the baseline $\mathrm{BS}_{\text {reference: }}$ we simply divide the number of bonds triggered by the number of forecasts made, i.e., $6 / 546=0.9$ percent. The resulting Brier skill score is $1-0.01 / 0.009=-0.11$. This score implies that for the entire set of catastrophe bond predictions, the skill of prediction is worse than using the 0.9 percent base rate for each and every forecast. Consistent with Figure 6, the number of extreme events predicted is higher than the number of extreme events that actually occur. In other words, for all the modeling work that is done to substantiate the business of catastrophe bonds, they do not have demonstrably accurate predictive power.

Simulating accuracy. As a complementary approach to assessing model accuracy, we simulated model performance by means of the catastrophe bond data we collected and, in particular, the parameter "probability of attachment"-the probability that the bond will be triggered. In catastrophe models, the event frequency of catastrophe natural events is modeled with a nonhomogeneous Poisson process (Chang, Lin, \& Yu, 2011; Dassios \& Jang, 2003; Jaimungal \& Wang, 2006), where events happen continuously and independently of one another and follow a Poisson distribution:

$$
P(k)=\frac{\lambda^{k} \mathrm{e}^{-\lambda}}{k !},
$$

where $P(k)$ is the probability of attachment, $k$ is the number of events, and $\lambda$ is the event rate. To create a simulation, one first must find the value $\lambda$ that determines the Poisson distribution for each catastrophe bond in the sample. We begin by recognizing that the probability of the bond being triggered is equal to one minus the probability of the bond not being triggered $(k=0)$. In this case, equation (3) becomes

$$
p(0)=\frac{\lambda^{0} \mathrm{e}^{-\lambda}}{0 !}=\mathrm{e}^{-\lambda} .
$$

Then, the probability of any event taking place is $p(k>0)=1-p(0)=1-\mathrm{e}^{-\lambda}$.

Transforming yields $\lambda=-\ln (1-p(k>0))$. In our case, as we are interested in one triggering event per catastrophe bond, $k=1$, and thus,

$$
\lambda=-\ln (1-p(1)) .
$$

Our dataset contains the probability attachment for each catastrophe bond ( $p(1)$ ), allowing us to solve for $\lambda$.

After obtaining the value of $\lambda$ for each of the bonds in our dataset, we constructed 1,000 simulated histories of all of these bonds. We used the value of $\lambda$ that we calculated to generate random Poisson distributions to determine whether each bond was triggered in each of these simulated histories. We then aggregated all the bonds in each simulated run to calculate the average number of triggered events and losses over our entire simulation. Results are presented in Figure 7A and 7B and are consistent with our Brier score analysis, which also revealed that forecasts are overly pessimistic, compared with actual events. This result reinforces our assessment that if catastrophe models are cameras, they are of poor quality.

\section{Are Catastrophe Models Engines?}

In this part of our analysis, we explore the possibility that catastrophe models are engines. The engine metaphor implies that changes in the theorization that underlies the models generate corresponding changes in how market actors price the financial instruments predicated on these models. Catastrophe risk modelers, of course, continuously refine and update their models, as new science is developed and additional data become available for calibration. Implicit in these improvements-but rarely stated-is an acceptance of the fact that prior models suffered from inaccuracy. But, to assess whether catastrophe models are engines, we first need to understand the contexts in which the models are modified and then explore the consequences of these modifications.

We have been unable to ascertain how frequently such modifications occur or to determine the magnitude of forecast changes that they generate, but we did identify two time periods when major model updates occurred. The first was in 2007, following Hurricane Katrina. A report from Lane Financial LLC, a consulting firm in the reinsurance sector, describes the hurricane's effects on catastrophe modelers as follows:

Katrina had caused a great deal of loss and a great deal of statistical-model soul searching. Had the models been sufficiently accurate in allowing for a storm of Katrina's intensity? The upshot was an extensive model revision by all three modeling companies during 2006. That is, by AIR Worldwide, EQECAT and RMS. They all adopted a similar convention to capture their reevaluation of the risk - they produced long term probabilities and introduced short term (or sensitivity) probabilities for certain risks and let the investors choose which to believe. (Lane \& Beckwith, 2007: 3) 


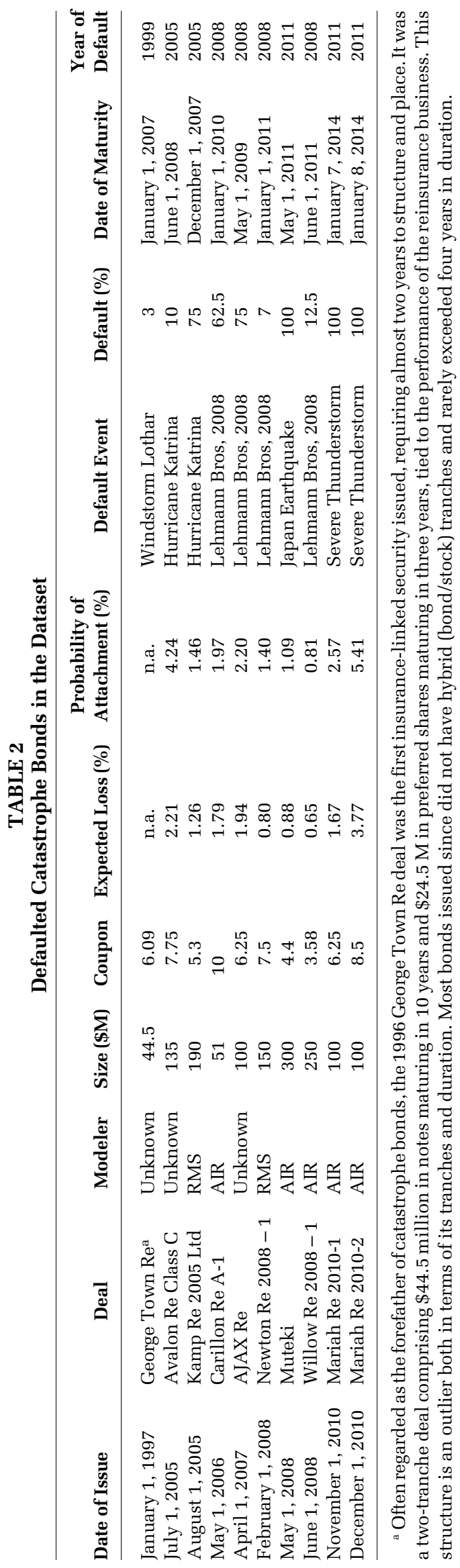


FIGURE 6

Catastrophe Bond Reliability Diagram

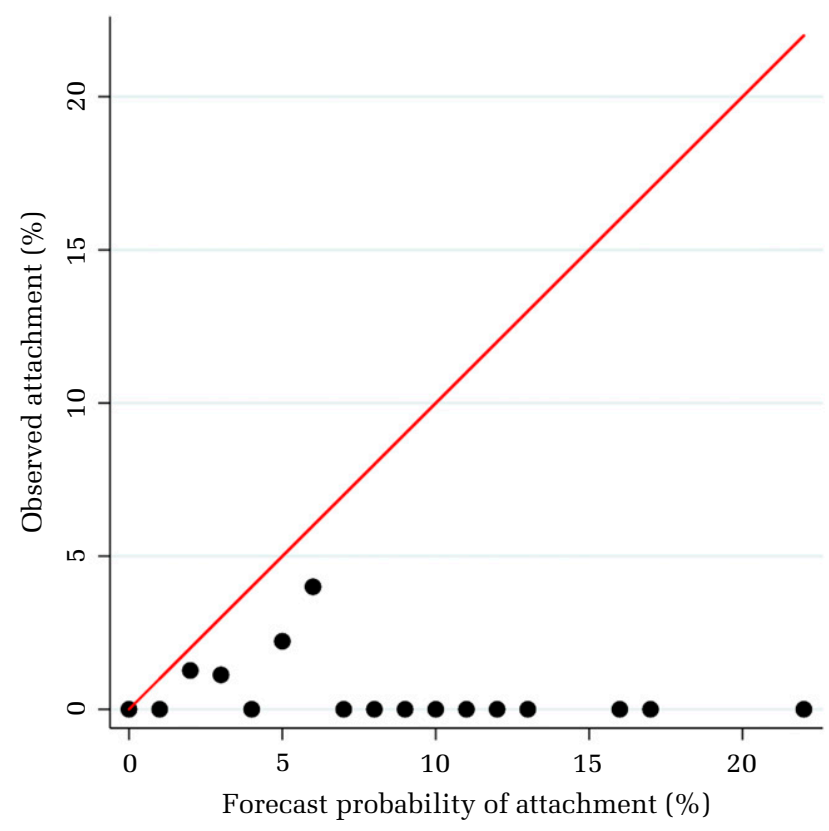

Whereas in 2007 all three central modelers introduced revisions following a costly catastrophic event, in 2011, RMS acted independently to refine its model. In February of that year, RMS changed the storm surge component in its model and also predicted an increase in hurricane activity due to warmer oceanic waters. The rationales for these changes, and their effect, were captured in the following quote:

Prior to the changes, RMS's model results were frequently included in cat bond offerings' prospectuses. Since the model change, however, RMS results have not been incorporated in U.S. hurricane cat bonds. AIR Worldwide has captured that business. Its model has reflected warmer seasurface temperatures since 2007, looking at historical average hurricane rates during periods of elevated sea-surface temperatures since 1900. RMS's is more forward-looking, predicting increasingly frequent and powerful hurricanes and subsequently larger losses and cat-bond payouts. (Hintze, 2013)

In the same interview, the managing director of RMS himself cautioned that the models his company provides are in fact indeterminate because "proving statistical validity requires 100 or more years of supporting data." Notwithstanding these acknowledgments of the limited predictive power of models, and the frequent changes they undergo, the models continue to be the basis of all catastrophe bond offerings.
Catastrophe risk modelers clearly take great pains to revisit and hone their modeling techniques, in an effort to improve their predictive power. Given this effort, one could reasonably assume that over time, the linkage between modeled losses (potential costs) and catastrophe bond spreads (potential benefits) would tighten. In other words, increasingly accurate modeling should translate into some measures of financial certitude, in an ongoing process of financial theory informing financial practice. We examine this postulate in the following paragraph.

What drives catastrophe bond pricing? Roughly two decades ago, when catastrophe bonds were first emerging, the yields they provided investors were described as "juicy" (Stovin-Bradford, 2015), offering investors a yield spread approximately twice the magnitude of equally rated corporate bonds (Dieckmann, 2011). One of the first bonds, issued by Residential Re, was approximately three times oversubscribed and closed at a price providing investors a return nine times greater than expected loss (Froot, 2001). The bond was not triggered. One explanation put forth for these puzzlingly lavish ratios was that the new, unfamiliar asset class necessitated particularly generous return rates to attract potential investors characterized by "ambiguity aversion, myopic loss aversion, and fixed costs of education" (Bantwal \& Kunreuther, 2000: 88).

Over time, these spreads have fluctuated but today are on aggregate roughly the same as 20 years ago. Figure 8A shows this progression. It also reveals that large fluctuations in spread (red line) occur after catastrophic events, both natural and financial. Spreads spiked in the aftermath of Katrina in 2005 and again following the 2008 financial crisis. A smaller fluctuation occurred after the Fukushima earthquake and tsunami of 2011, following which one bond defaulted. At the same time, the mean expected loss has been stable over these past two decades (blue line).

Internal dynamics of the insurance market explain how these spreads can be volatile, whereas expected loss remains stable. Reinsurance constantly cycles between "hard" and "soft" markets. Hard markets appear after large loss events, when the entire industry experiences a liquidity crunch following a high number of payouts to customer claims (Johnson, 2014). Conversely, soft markets occur after years when payouts have been lower than expected, easing the pressure on insurance premiums and catastrophe bond yields. Figure 8A reveals that catastrophe bonds follow precisely this dynamic. Cedents offer higher return rates in hard markets to obtain capital to make payouts. In other words, higher spreads are not at all related to changes in expected losses or in the underlying catastrophe risk models. 
FIGURE 7

(A) Number of Defaults, 1,000 Simulated Histories; (B) Losses, 1,000 Simulated Histories

A

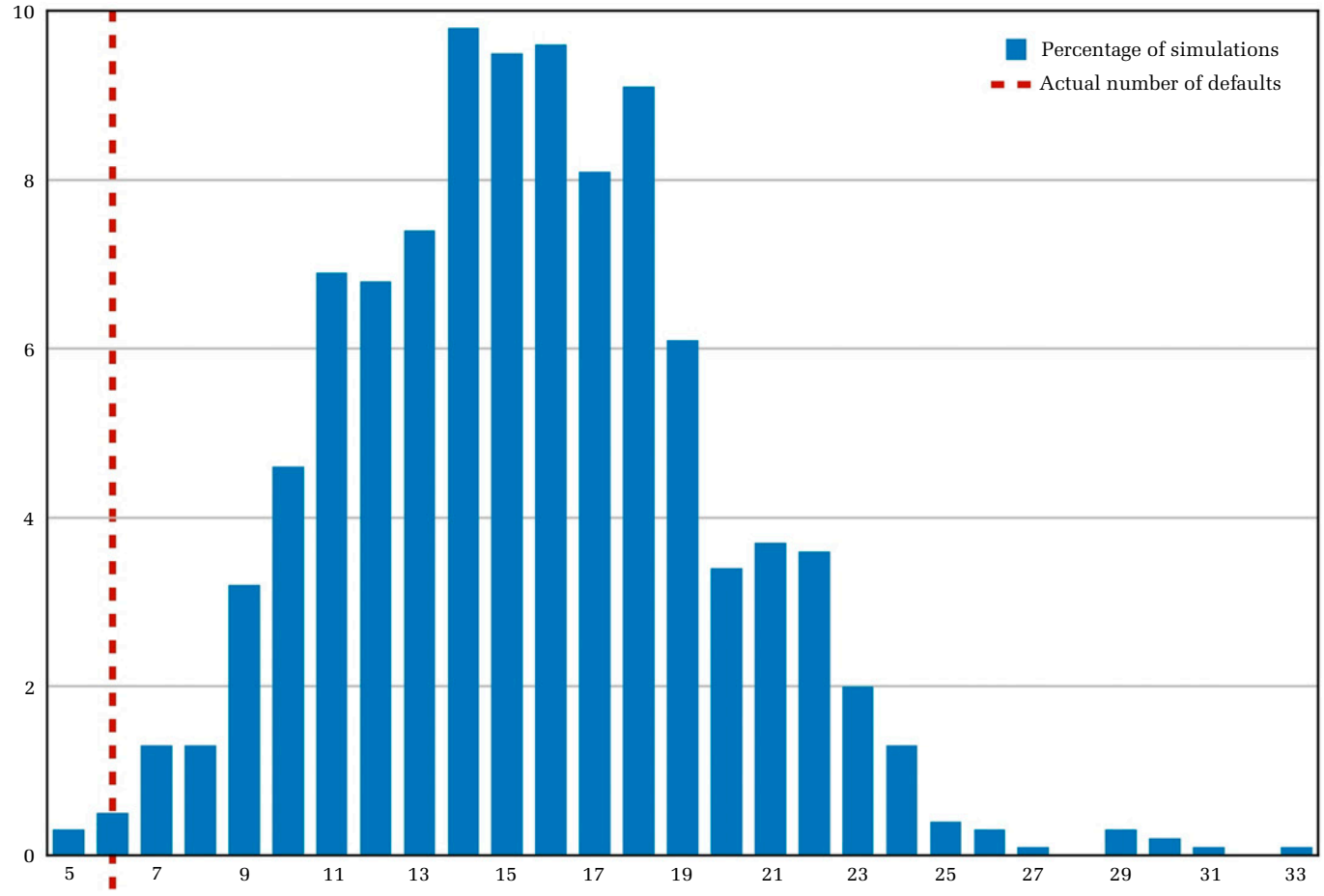

B

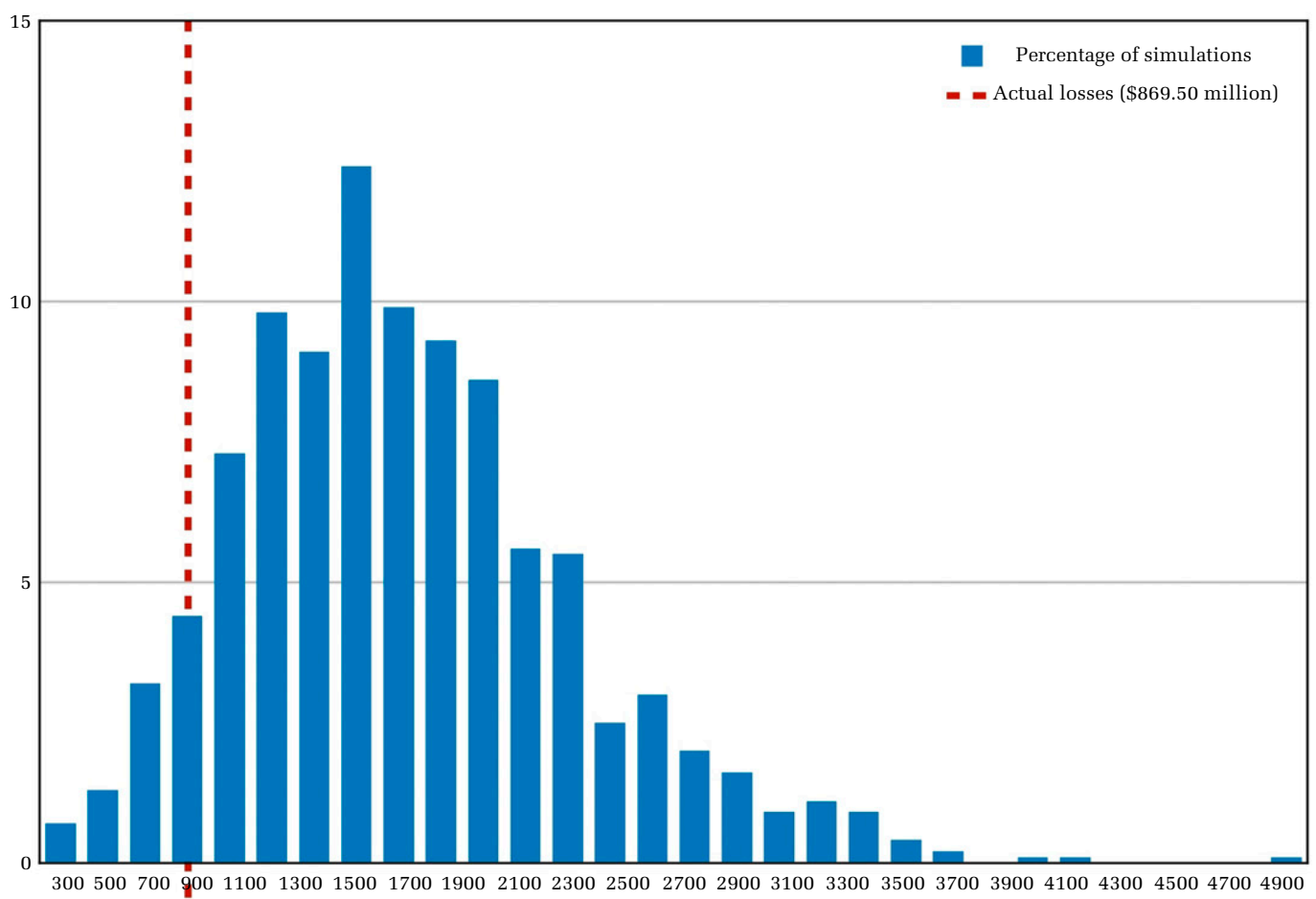




\section{FIGURE 8}

(A) Performance of the Cat Bond Market (Yearly Mean Values); (B) Catastrophe Bond and Similarly Rated Corporate Bond Spreads (Yearly Mean Values)

A

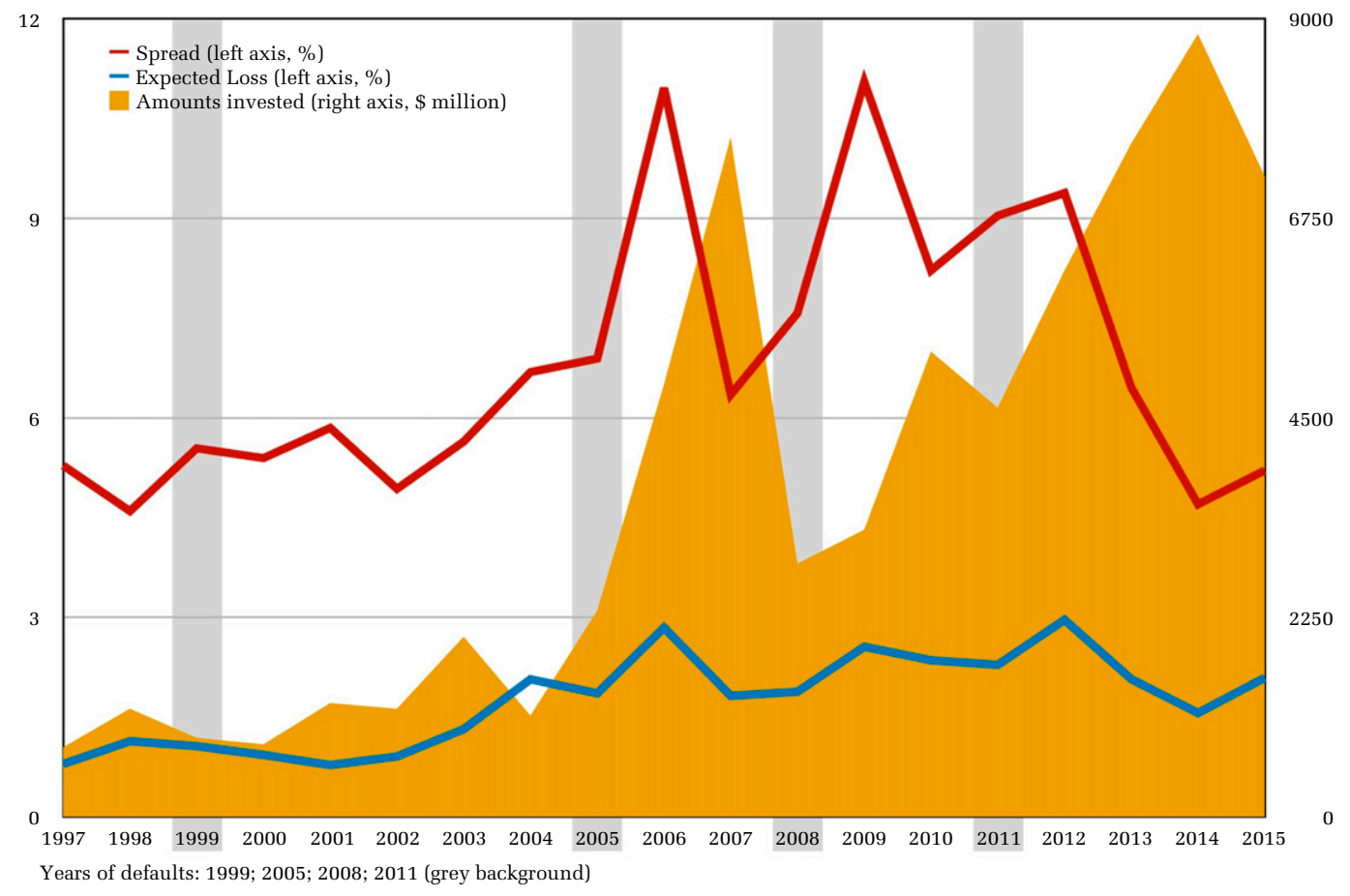

B

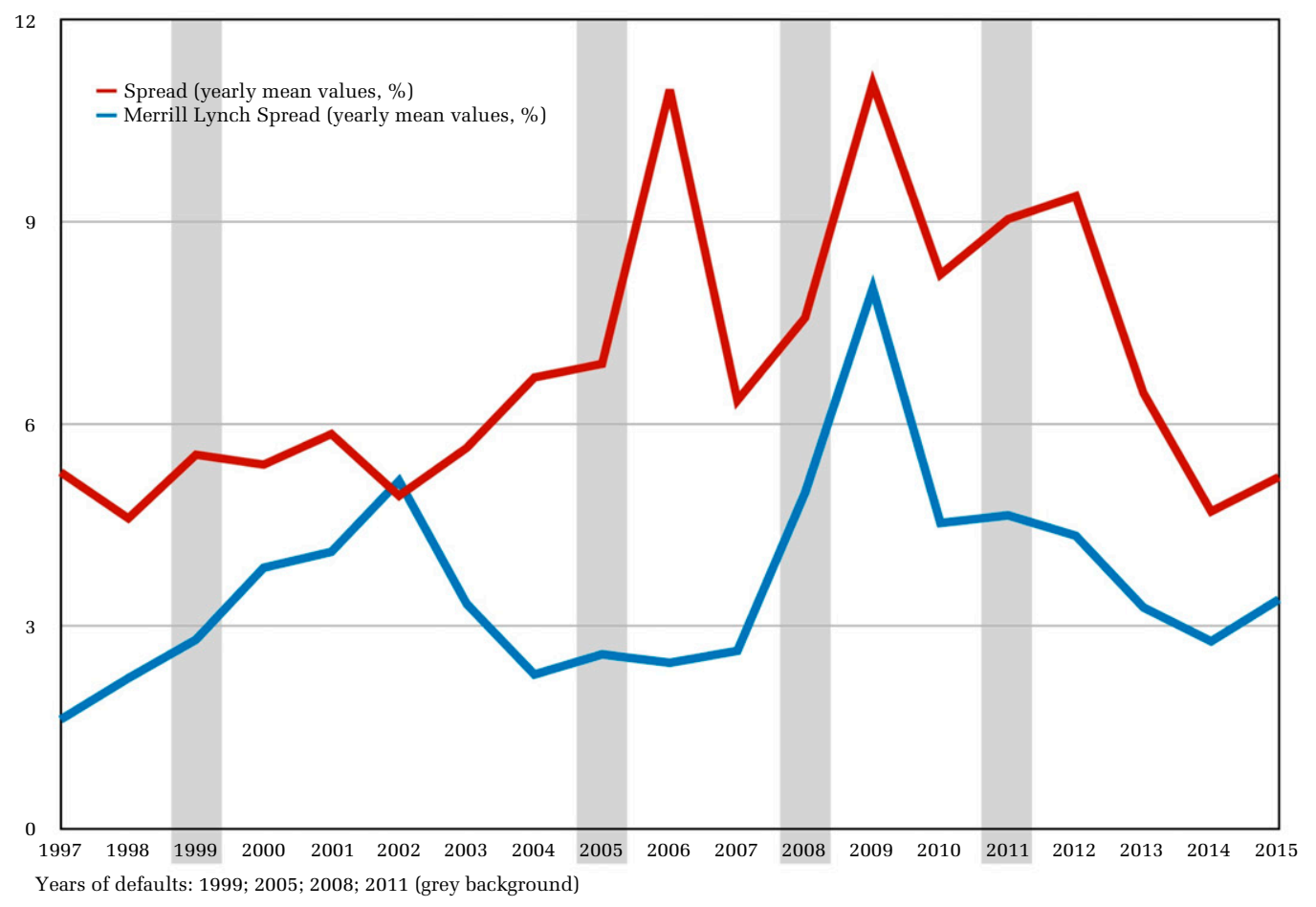


Also apparent from Figure 8A is a pattern of sizable and consistent growth in the catastrophe bond market (ochre area), except for a dip following the financial crisis, an event unrelated to the natural catastrophe risk. Growth was so substantial that by 2013, the market had flipped from a buyers' market to a sellers' market. Catastrophe bond offerings had routinely become oversubscribed, and yield spreads declined correspondingly. Coupon rates were priced in the bottom of the range that was suggested during roadshows, at times coming in even below the range (Fitch Reinsurance, 2014). This, in turn, put downward pressure on traditional reinsurance offerings, to the consternation of Warren Buffet and others.

"Mr. Buffett used to brag about the scale and profitability of the [reinsurance] business. At last year's Berkshire annual meeting, Mr. Buffett complained to shareholders that reinsurance has become 'a fashionable asset class.' Faced with lower prices and poor returns, Berkshire is doing fewer deals. Mr. Ehrhart, the Aon executive, says he used to call the profit squeeze 'the battle of six and 16.' Reinsurers historically aimed for returns of 16 percent a year. The pension funds snapping up cat bonds are happy with just 6 percent." (Scism \& Das, 2016).

Indeed, over time, as catastrophe bonds have become more mainstream, their spread has come to closely resemble that of similarly rated corporate bonds (see Figure 8B). In soft markets, they too now tack to broader economic conditions and availability of capital, albeit at a premium, driven apparently by investor belief that corporate bonds are, unlike catastrophe bonds, immune to total loss (Lane \& Beckwith, 2002).

These three influences-macroeconomic conditions, liquidity in the insurance industry, and the meeting of supply and demand-are in no way revelatory. They are vitally important to consider, however, because they show that the factors that have been driving catastrophe bond pricing over the past 20 years are not an outcome of financial theorization, despite the sophistication of catastrophe modeling. Movements in prices are driven by mundane economic forces. Catastrophe models, unlike derivatives (MacKenzie \& Millo, 2003), are not engines.

\section{IMPLICATIONS}

“It's crazy that we've only [got data] for 40 years and talk about one-in-500 year return periods. How the fuck am I supposed to know [whether a model is accurate]?” (Anonymous reinsurer, quoted in Jarzabkowski et al., 2015: 79).
Our analysis has demonstrated, at length, several points worth reiterating. First, catastrophe models do not predict extreme events better than guesswork. Second, catastrophe models evolve as the underlying science improves, yet nonetheless do not become demonstrably more accurate. And third, the returns that they provide investors are driven largely by exogenous economic factors, rather than by the catastrophe risk which underlies the bond. Perhaps, it is no surprise that in the insurance industry many see catastrophe models as "useless" (Jarzabkowski et al., 2015: 79).

Is such a conclusion warranted, however? Notwithstanding their shortcomings, the logic of the models and the math that underlies these bonds are, in fact, thoughtful and plausibly correct. Because the variables in the formulas are not known with precision, a "good" model may actually have very little predictive power because it has extremely large confidence intervals. Consequently, over a horizon of several years, catastrophe models simply cannot be wrong. "[Catastrophe] models perform a peculiar epistemological magic. Because their object exists only in the probabilistic future, they are never absolutely falsifiable-yet by the same token, they can always be improved via the incorporation of new observations and science." (Johnson, 2015: 2511).

Nonetheless, it is reasonable to question whether improvements attained through incorporation of new observations and science will substantively increase predictive power. Modeling challenges are expected to increase as the world heats (Surminski, Bouwer, \& Linnerooth-Bayer, 2016). These challenges arise for two reasons. The first is a violation of the assumption of stationarity, which underlies catastrophe models. When invoking stationarity, modelers assume that the statistical distribution of events in the past will remain constant moving forward (Milly et al., 2008; Temple, 2017). Stationarity underpins the appropriateness of using historical events to calibrate and validate climate models. And yet, evidence suggests that hurricane (Emanuel, 2017), forest fire (Abatzoglou \& Williams, 2016; Turco et al., 2018), and flooding (Alfieri et al., 2017) incidents in a warmer world will differ considerably from past patterns.

A second, even greater challenge to modeling arises when acknowledging that climatic patterns may tip. Whereas catastrophe models have focused to date on regions that are particularly prone to storms and droughts, extreme weather patterns may shift dramatically on a warmer planet. Unprecedented extreme events catch insurers unprepared. For example, a "gray swan" wildfire hit Fort McMurray and its environs in 2016, causing \$3B in insurance damages. At the time, actuaries believed that wildfire risk in the area was nonexistent, and it was not factored into premiums. Maurice Tulloch, the chief executive of 
Aviva PLC's international insurance division, said: "The previous models wouldn't have envisioned it." (Hope \& Friedman, 2018). Climatologists are now attempting to forecast sui generis events such as the advent of gray swan tropical cyclones: high-impact storms that have no historical precedent but are foreseeable by integrating theories from climate physics with historical data patterns. Gray swan typhoons have recently been deemed plausible in the Persian Gulf, a region where extreme storms have never been recorded, but which climatologists say may become increasingly likely as the planet warms (Lin \& Emanuel, 2016). At this level of ignorance and uncertainty, insurers and financiers would likely be loath to attempt to place a monetary value on the likelihood and damages of such a disaster.

Overall, inasmuch as modelers accumulate knowledge and improve their modeling, these efforts may be overshadowed by rapid climatological shifts and the forecasting uncertainty that they generate. It is unclear whether the "cameras" that future modelers will develop will be any less indeterminate than current ones. There appears to be an upper bound on the capacity of modeling and risk management to reduce uncertainty when it comes to costly, rare events.

\section{The Role of Ignorance}

Interestingly, actors in the catastrophe bond market are under no illusion about their accuracy. John Seo, a hedge fund manager who was instrumental in establishing the catastrophe bond market, has suggested that bond prices "didn't need to be exactly right, just sort of right" (Lewis, 2007: 626). In the world of catastrophe bonds, as in statistics, the aphorism "all models are wrong, some are useful," seems to apply. Actors use models that are state-of-the-art yet inaccurate, built from highly sophisticated expertise yet yielding indeterminacy, acknowledged as flawed, yet indispensable for market transactions to occur.

If ontological certainty, in finance, takes a back seat to utility, this begs the question of what utility exactly catastrophe models provide. One possibility is that catastrophe models do not directly determine value, but they do help in other ways. In particular, they may be used even when model users dislike or are skeptical of them, if not least for the coordination and communication affordances they provide (MacKenzie \& Spears, 2014a), to “enable tradability” (Davis \& Kim, 2015: 207). If this is true, then market actors who initiate, buy, and sell catastrophe bonds create a social arrangement that accepts, and is indeed founded on, ignorance that is irreducible (Faber, Manstetten, \& Proops, 1992).

This tentative proposition is aligned with research in the emerging interdisciplinary field of agnotology, or the study of ignorance (Croissant, 2014; McGoey, 2012a, 2012b; Proctor, 2008; Rescher, 2009). One of agnotology's central claims is that ignorance is not necessarily something to be eradicated, and may in some instances be useful. In particular, ignorance can help get things done. Ignorance can help us "see" things clearly, as in the case of blind auditions for musicians (Goldin \& Rouse, 2000). Similarly, blind reviews for academic articles help observers focus on the most salient aspects of what they need to evaluate. Purposeful ignorance is equivalent to the conscious unburdening of the weight of heuristics and accumulated wisdom, and can yield improved outcomes.

Driving this point to its logical conclusion, Smithson (2008: 221) argued that expertise and particularly specialization is a "social ignorance arrangement." Specialization distributes expertise across populations, concentrating narrow domains of knowledge among certain groups while at the same time expanding the ignorance of nonexperts. In catastrophe modeling, as expertise in hazard, engineering, and economic models becomes more technical and intricate, so too does the ignorance of managers, investors, regulators, and other evaluators of this expertise. Nonspecialists willfully become more ignorant, commensurately more reliant on the expertise of specialists, less aware of underlying assumptions and nuance (Knorr-Cetina, 1999; MacKenzie, 1996). And yet, because the logic of relying on specialization to increase knowledge is compelling, the resultant social arrangement is sustained.

Notably, social arrangements of willful ignorance appear to inform the evaluation cultures that shape trading decisions in financial markets (Lange, 2016; MacKenzie \& Spears, 2014b). These arrangements seem to induce market actors to transact without a full comprehension of the risks involved, a dynamic that appears to have been at play in the 2008 financial crisis (MacKenzie, 2011). The expert knowledge required to parse mortgage-backed securities may have led to traders not understanding them fully (Ghent, Torous, \& Valkanov, 2014), even though they could have (and some did) (Fligstein \& Goldstein, 2010). However, in catastrophe bonds, even if one masters the math and the jargon, ignorance cannot be eradicated. If this is indeed the case, it is worthwhile considering the implications that may derive from the use of catastrophe bonds and other financial tools to promote sustainable development.

\section{Ignorance and Value Capture}

Our analysis suggests that, to date, catastrophe bonds have been placed at price points that disfavor the end users of insurance products. Surplus 
revenues have made their way to catastrophe bond investors because the number of bonds triggered has been lower than predicted by the models. Although it is impossible to determine whether this is a result of modeling flaws, biases, or the stochastic manner in which catastrophes have occurred, clearly these rents have not been channeled into efforts toward addressing the SDGs. The monetary rewards of ignorance have, so far, trickled up, not down.

Clearly, it is quite plausible that in the future, bonds will be triggered more frequently and will provide much needed succor to claimants in dire straits. ${ }^{8}$ Were this to occur, it would appear to be an example of financialization contributing directly to social welfare. It is far from certain, however, whether institutional investors would remain invested in catastrophe bonds if they were to begin triggering more frequently. As we have shown, institutional investors' ongoing interest in catastrophe risk is not entirely unrelated to the confluence of economic conditions following the 2008 financial crisis. A heady mix of low interest rates, high cash reserves, and a good initial track-record that provided superlative returns has attracted investors with higher risk appetites and leveraged assets, suggesting increased speculative, rather than insurance interest in these instruments (Cohn, 2014), and leading some to worry about a bubble in the catastrophe bond market. In any case, if new entry and competitive pressures continue to reduce spreads, investors are likely to seek returns elsewhere, quite possibly in domains unrelated to sustainability. All told, the social benefit attainable through harnessing financial innovation to manage extreme risk may well be fleeting, or even illusory.

Our conclusions thus beg the question of whether financial innovation is an appropriate avenue for tackling the most uncertain of hazards likely to materialize in an increasingly unstable planetary environment. It is unclear whether insurers, regulators, and the general public should continue to place their confidence in financial solutions that are predicated on infrequent events and low interest rates. Catastrophe bonds are increasingly used at the sovereign level in developing

${ }^{8}$ Our data collection ended in 2016, before the highprofile catastrophes of 2017 (Hurricanes Irma, Harvey, and Maria and others) and 2018 (California wildfires) had occurred. As many as 19 separate CAT bond tranches may have been triggered, yet losses are still not known, because many insurance claims remain unresolved. At the time of writing, \$1.05 billion in outstanding issuance is vulnerable to losses (Artemis, 2019a), revised from an initial \$1.4 billion from 2017 alone (Polacek, 2018). At the same time, new CAT bond issuance in 2018 reached $\$ 13.9$ billion, rivaling 2017's record year of \$12.6 billion, and Q1 2019 $\$ 2.8$ billion issuance was the second most active Q1 in the market's history (Artemis, 2019b, 2019c). economies such as Turkey, across the Caribbean, and in Mexico (Ghesquiere \& Mahul, 2010; Marsh \& McLennan, 2018). With the returns that bonds covering these economies provide, it is important to ensure that they reduce precarity, rather than increasing it.

\section{Other Tools}

Of course, other avenues for reducing risk and providing post-catastrophe aid do exist. In the context of disaster response, which is notoriously haphazard and inefficient, the assistance provided by governments and aid organizations is often slower than desired (Ballesteros, Useem, \& Wry, 2017). But this does not mean that governments and societies are best served by increasing their reliance on market actors. One alternative set of solutions involves better preparation in the form of scenario planning, preemptive financial allocations, and de-politization of disaster relief efforts (Clarke \& Dercon, 2016). Collaboration between government and the private sector also seems to be a promising approach. An example is Flood Re: a partnership between the U.K. government and insurers through which reinsurance is subsidized by a tax levied on all insurers that offer home insurance in the country (Christophers, 2019).

In addition to risk transfer, financial tools that promote risk reduction can also be used, following the maxim that an ounce of prevention is worth a pound of cure. Preemptive construction of infrastructure that will reduce the impact of rising sea levels and higher storm surges will reduce future rebuilding costs (Mechler et al., 2014). Financial engineering can make such investments attractive. The so-called resilience bonds would allow a city, e.g., to arrange for an insurance company to provide financing to build higher seawalls to prevent flooding. A seawall would reduce the premium that an insurance company demands for covering the city's catastrophe risk, and freeing funds from the city's budgetary line item would allow it to spend the money for construction (Ruggeri, 2017). The World Resources Institute has developed a forest resilience bond, which takes capital from private investors and invests it in forest restoration to reduce the risk of wildfire (Koren, 2018). Beneficiaries pay investors back over time from the savings expected to accrue as fires and the damage they leave behind both decline. As these and other forms of financial innovation become available, it is important to assess which suites of products most effectively promote desirable planetary and social outcomes.

\section{CONCLUSION: FINANCING THE SDGS}

The promise and perils associated with catastrophe bonds are not unlike those associated with other 
financial innovation associated with the SDGs. For example, Sullivan and Hannis (2017) describe a form of financial innovation known as biodiversity offsetting. It allows developers that create "unavoidable" harm through habitat destruction to compensate for these impacts by paying for an "equivalent" amount of habitat conservation elsewhere. Potentially, future markets will allow actors to trade in "biodiversity units." On other fronts, social impact bonds are financial instruments in which investors provide capital to nonprofit organizations that deliver social programs, such as reducing recidivism and providing special needs education (Knowledge@Wharton, 2012). If the nonprofit meets predefined metrics, the government reduces the long-term cost of public services and can thereby pay investors back, plus a return. If the nonprofit fails in meeting its objectives, the investors get no repayment.

There is no shortage of reasons to find these financial innovations objectionable. From a normative perspective, they demand that individuals and societies tackle uncomfortable questions regarding the dividing line between the sacred and the profane, morals, and markets (Zelizer, 1979). Just because habitats and catastrophes can be transformed into tradable units, does not mean that they have to be. Other possibilities exist, although perhaps they are increasingly difficult to imagine in societies dominated by markets (Davis, 2009).

To the extent that financial innovation is encouraged, it would be wise to consider designing tools and markets in ways that truly encourage sustainable development and discourage excess profit-making. Instruments such as catastrophe bonds, social impact bonds, and biodiversity markets all use intricate models based on the best available evidence, and yet their accuracy is hard to discern, particularly in the short term. Moreover, they are offered to institutional investors and are not traded via open markets. These attributes make them less than ideal candidates for informed, inclusive trading, which thrives on frictionless transactions in information rich environments (Zuckerman, 2010). If financial innovations are to be used for tackling the SDGs, we would argue that it is particularly important for them to be designed robustly, with mechanisms that incentivize actors to truly create social value. Improving transparency and accessibility, while not a panacea, can allow actors with complementary sources of expertise to enter these markets and influence the social outcomes they generate.

Financial innovation may not be effective everywhere and should not be deployed haphazardly. It can create the greatest good when its application is relatively simple and straightforward, relying more on common sense than irreducible ignorance.

\section{REFERENCES}

Abatzoglou, J. T., \& Williams, A. P. 2016. Impact of anthropogenic climate change on wildfire across western US forests. Proceedings of the National Academy of Sciences, 113(42): 11770-11775.

Ackerman, F., \& Heinzerling, L. 2004. Priceless: On knowing the price of everything and the value of nothing. New York: New Press.

AIR Worldwide. 2017. The AIR hurricane model for the U.S. V16.0.0 as implemented in Touchstone ${ }^{\circledR}$ V4.1.0. Presentation to the Florida Commission on Hurricane Loss Projection Methodology, Tallahassee, FL, May 10.

Alfieri, L., Bisselink, B., Dottori, F., Naumann, G., de Roo, A., Salamon, P., Wyser, K., \& Feyen, L. 2017. Global projections of river flood risk in a warmer world. Earth's Future, 5(2): 171-182.

Artemis. 2018. Cat bond \& ILS issuance passes \$5.7bn in 2018, market hits \$33bn in size. https://www.artemis. bm/news/cat-bond-ils-issuance-passes-5-7bn-in-2018market-hits-33bn-in-size/. Accessed December 5, 2019.

Artemis. 2019a. Cat bond loss expectations rise on going creep. https://www.artemis.bm/news/cat-bond-lossexpectations-rise-on-ongoing-creep/. Accessed November 29, 2019.

Artemis. 2019b. Catastrophe bonds \& ILS issued and outstanding by year. https://www.artemis.bm/dashboard/catastrophe-bonds-ils-issued-and-outstandingby-year/. Accessed November 29, 2019.

Artemis. 2019c. Q1 2019 catastrophe bonds \& ILS Market report. https://www.artemis.bm/wp-content/uploads/ 2019/03/q1-2019-cat-bond-ils-market-report.pdf. Accessed November 29, 2019.

Association of British Insurers. 2005. Financial risks of climate change. London, UK: ABI.

Austin, J. L. 1976. How to do things with words (2nd ed.). Oxford: Oxford University Press.

Ballesteros, L., Useem, M., \& Wry, T. 2017. Masters of disasters? An empirical analysis of how societies benefit from corporate disaster aid. Academy of Management Journal, 60(5): 1682-1708.

Bantwal, V. J., \& Kunreuther, H. C. 2000. A cat bond premium puzzle? Journal of Psychology and Financial Markets, 1(1): 76-91.

Bateman, M., \& Chang, H.-J. 2012. Microfinance and the illusion of development: From hubris to nemesis in thirty years. World Economic Review, 2012(1): $13-36$.

Born, P., \& Viscusi, W. K. 2006. The catastrophic effects of natural disasters on insurance markets. Journal of Risk and Uncertainty, 33(1-2): 55-72. 
Boyer, M. M., \& Dupont-Courtade, T. 2015. The structure of reinsurance contracts. The Geneva Papers on Risk and Insurance-Issues and Practice, 40(3): 474-492.

Bradley, A. A., Schwartz, S. S., \& Hashino, T. 2008. Sampling uncertainty and confidence intervals for the Brier score and Brier skill score. Weather and Forecasting, 23(5): 992-1006.

Braun, A. 2016. Pricing in the primary market for cat bonds: New empirical evidence. Journal of Risk and Insurance, 83(4): 811-847.

Brier, G. W. 1950. Verification of forecasts expressed in terms of probability. Monthly Weather Review, 78(1): 1-3.

Business and Sustainable Development Commission. 2017. Better business, better world. London: BSDC.

Cabantous, L., \& Dupont-Courtade, T. 2015. What is a catastrophe model worth? The (e)valuative practices of cat analysts in insurance companies. In M. Kornberger, L. Justesen, J. Mouritsen, \& A. K. Madsen (Eds.), Making things valuable: 167-186. Oxford, UK: Oxford University Press.

Carruthers, B. G., \& Kim, J.-C. 2011. The sociology of finance. Annual Review of Sociology, 37: 239-259.

Centeno, M. A., Nag, M., Patterson, T. S., Shaver, A., \& Windawi, A. J. 2015. The emergence of global systemic risk. Annual Review of Sociology, 41: 65-85.

Chang, C. C., Lin, S. K., \& Yu, M. T. 2011. Valuation of catastrophe equity puts with Markov-modulated Poisson processes. Journal of Risk and Insurance, 78(2): 447-473.

Chen, C. 2014. Buffett warning unheeded as catastrophe bond sales climb. https://www.bloomberg.com/news/ articles/2014-06-17/buffett-warning-unheeded-ascatastrophe-bond-sales-climb. Accessed November 28, 2019.

Christophers, B. 2019. The allusive market: Insurance of flood risk in neoliberal Britain. Economy and Society, 48(1): 1-29.

Clark, K. M. 2002. The use of computer modeling in estimating and managing future catastrophe losses. Geneva Papers on Risk and Insurance - Issues and Practice, 27(2): 181-195.

Clarke, D. J., \& Dercon, S. 2016. Dull disasters? How planning ahead will make a difference. Oxford: Oxford University Press.

Cleetus, R. 2013. Overwhelming risk: Rethinking flood insurance in a world of rising seas. Cambridge, MA: Union of Concerned Scientists.

Clifford, A. A. 1973. Multivariate error analysis: A handbook of error propagation and calculation in manyparameter system. New York: Wiley.

Cohn, C. 2014. Hedge funds move into catastrophe reinsurance. Insurance Journal. https:/www.insurancejournal.com/ news/international/2014/10/29/345196.htm. Accessed November 28, 2019.

Costello, C., Gaines, S., \& Gerber, L. R. 2012. Conservation science: A market approach to saving the whales. Nature, 481(7380): 139-140.

Coumou, D., \& Rahmstorf, S. 2012. A decade of weather extremes. Nature Climate Change, 2(7): 491-496.

Croissant, J. L. 2014. Agnotology: Ignorance and absence or towards a sociology of things that aren't there. Social Epistemology, 28(1): 4-25.

Culp, C. L. 2006. Structured finance and insurance: The ART of managing capital and risk. New York: Wiley.

Cummins, J. D., \& Weiss, M. A. 2009. Convergence of insurance and financial markets: Hybrid and securitized risk-transfer solutions. Journal of Risk and Insurance, 76(3): 493-545.

Dassios, A., \& Jang, J.-W. 2003. Pricing of catastrophe reinsurance and derivatives using the Cox process with shot noise intensity. Finance and Stochastics, 7(1): 73-95.

Davis, G. F. 2009. Managed by the markets: How finance re-shaped America. Oxford: Oxford University Press.

Davis, G. F., \& Kim, S. 2015. Financialization of the economy. Annual Review of Sociology, 41(1): 203-221.

Denuit, M., Dhaene, J., Goovaerts, M., \& Kaas, R. 2015. Actuarial theory for dependent risks: Measures, orders and models. New York: Wiley.

Dickson, J. 2013. Remarks by Superintendent Julie Dickson Office of the Superintendent of Financial Institutions Canada (OSFI) to the 2013 National Insurance Conference of Canada, September 23, 2013 ed. Gatineau, QC.

Dieckmann, S. 2011. A consumption-based evaluation of the cat bond market Advances in Pacific Basin Business, Economics and Finance, Vol. 7, Bingley, UK: Emerald, pp. 1-26.

DNV GL, UN Global Compact, \& Sustainia. 2018. Global opportunity report Oslo, Norway: DNV GL AS.

Emanuel, K. 2017. Will global warming make hurricane forecasting more difficult? Bulletin of the American Meteorological Society, 98(3): 495-501.

Faber, M., Manstetten, R., \& Proops, J. L. R. 1992. Humankind and the environment: An anatomy of surprise and ignorance. Environmental Values, 1(3): 217-241.

Fitch Reinsurance. 2014. Global reinsurance guide 2014 New York: Fitch Ratings.

Fligstein, N., \& Goldstein, A. 2010. The anatomy of the mortgage securitization crisis. In M. Lounsbury, \& P. M. Hirsch (Eds.), Markets on trial: The economic 
sociology of the U.S. financial crisis, vol. 30A: 29-70. Bingham, UK: Emerald.

Foale, S., Dyer, M., \& Kinch, J. 2016. The value of tropical biodiversity in rural Melanesia. Valuation Studies, 4(1): 11-39.

Froot, K. A. 2001. The market for catastrophe risk: A clinical examination. Journal of Financial Economics, 60(2): 529-571.

Ghent, A. C., Torous, W. N., \& Valkanov, R. I. 2014. Complexity in structured finance: Financial wizardry or smoke and mirrors? Available at SSRN: https://ssrn.com/abstract=2325835.

Ghesquiere, F., \& Mahul, O. 2010. Financial protection of the state against natural disasters: $A$ primer. Policy Research Working Paper 5429. Washington, DC: World Bank.

Goldin, C., \& Rouse, C. 2000. Orchestrating impartiality: The impact of "blind" auditions on female musicians. American Economic Review, 90(4): 715-741.

GRI, UN Global Compact, \& WBCSD. 2015. SDG compass: The guide for business action on the SDGs https://sdgcompass.org/wp-content/uploads/2015/ 12/019104_SDG_Compass_Guide_2015.pdf. Accessed November 28, 2019.

Grossi, P., \& Kunreuther, H. (Eds.). 2005. Catastrophe modeling: A new approach to managing risk. New York: Springer.

Gründl, H., Dong, M. I., \& Gal, J. 2017. The evolution of insurer portfolio investment strategies for long-term investing. OECD Journal: Financial Market Trends, 2016(2): 1-55.

Gürtler, M., Hibbeln, M., \& Winkelvos, C. 2016. The impact of the financial crisis and natural catastrophes on CAT bonds. Journal of Risk and Insurance, 83(3): 579-612.

Harding, R. 2014. World Bank sells first ever 'cat bond'. http:// pubdocs.worldbank.org/en/623931528830371378/ FTarticle-WorldBankSellsFirstCatBond-June2014.pdf. Accessed November 28, 2019.

Hart, S. L., \& Christensen, C. M. 2002. The great leap: Driving innovation from the base of the Pyramid. Sloan Management Review, 44(1): 51-56.

Hintze, J. 2013. The uncorrelated attraction of cat bonds. Jersey City, NJ: Global Association of Risk Professionals. Available at https://web.archive.org/web/20130525044150/ http:/www.garp.org/risk-news-and-resources/2013/ february/the-uncorrelated-attraction-of-cat-bonds.aspx. Accessed November 28, 2019.

Hoffman, F. O., \& Hammonds, J. S. 1994. Propagation of uncertainty in risk assessments: The need to distinguish between uncertainty due to lack of knowledge and uncertainty due to variability. Risk Analysis, 14(5): 707-712.

Hope, B., \& Friedman, N. 2018. Climate change is forcing the insurance industry to recalculate, Wall Street Journal. October 2.

Hsu, W.-r., \& Murphy, A. H. 1986. The attributes diagram: A geometrical framework for assessing the quality of probability forecasts. International Journal of Forecasting, 2(3): 285-293.

Jaeggi, O. 2015. The insurance industry wants a world that is sustainable and insurable. MIT Sloan Management Review.

Jaimungal, S., \& Wang, T. 2006. Catastrophe options with stochastic interest rates and compound Poisson losses. Insurance: Mathematics and Economics, 38(3): 469-483.

Jarzabkowski, P., Bednarek, R., \& Spee, P. 2015. Making a market for acts of god: The practice of risk-trading in the global reinsurance industry. Oxford: Oxford University Press.

Johnson, L. 2014. Geographies of securitized catastrophe risk and the implications of climate change. Economic Geography, 90(2): 155-185.

Johnson, L. 2015. Catastrophic fixes: Cyclical devaluation and accumulation through climate change impacts. Environment and Planning A, 47(12): 2503-2521.

Johnson, S. 2013. Catastrophe bonds prove anything but a disaster. Financial Times.

Khalamayzer, A. 2017. How green bonds can bridge infrastructure financing gaps. Greenbiz. https:// www.greenbiz.com/article/how-green-bonds-can-bridgeinfrastructure-financing-gaps. Accessed November 28, 2019.

Knorr-Cetina, K. 1999. Epistemic cultures: How the sciences make knowledge. Cambridge, MA: Harvard University Press.

Knowledge@Wharton. 2012. Social finance's tracy palandjian on the next generation of responsible investing. Knowledge@Wharton. https://knowledge. wharton.upenn.edu/article/social-finances-tracypalandjian-on-the-next-generation-of-responsibleinvesting/. Accessed November 28, 2019.

Knox-Hayes, J. 2015. Towards a moral socio-environmental economy: A reconsideration of values. Geoforum, 65: 297-300.

Koren, J. R. 2018. Start-up Blue Forest secures funding for first privately financed forest fire bond. Los Angeles Times November 1.

Lalonde, D. A., \& Karsenti, P. 2008. So you want to issue a cat bond. AIRCurrents, February. https:// www.air-worldwide.com/_public/NewsData/001410/ AIRCurrents_CatBond.pdf. Accessed November 28, 2019. 
Lane, M. N., \& Beckwith, R. G. 2002. 2002 review of trends in insurance securitization. Trade Notes. Kenilworth, IL: Lane Financial, LLC.

Lane, M. N., \& Beckwith, R. G. 2007. That was the year that was! The 2007 review of the insurance securitization market. Trade Notes. Wilmette, IL: Lane Financial, LLC.

Lange, A.-C. 2016. Organizational ignorance: An ethnographic study of high-frequency trading. Economy and Society, 45(2): 230-250.

Lewis, M. 2007. Nature's Casino. New York Times. August 26: 626.

Lin, N., \& Emanuel, K. 2016. Grey swan tropical cyclones. Nature Climate Change, 6(1): 106-111.

Linnenluecke, M. K., Smith, T., \& McKnight, B. 2016. Environmental finance: A research agenda for interdisciplinary finance research. Economic Modelling, 59: 124-130.

MacKenzie, D. 1996. How do we know the properties of artefacts? Applying the sociology of knowledge to technology. In R. Fox (Ed.), Technological change: Methods and themes in the history of technology: 247-264. London: Routledge.

MacKenzie, D. 2006. An engine, not a camera: How financial models shape markets. Cambridge: MIT Press.

MacKenzie, D. 2011. The credit crisis as a problem in the sociology of knowledge. American Journal of Sociology, 116(6): 1778-1841.

MacKenzie, D., \& Millo, Y. 2003. Constructing a market, performing theory: The historical sociology of a financial derivatives exchange. American Journal of Sociology, 109(1): 107-145.

MacKenzie, D., \& Spears, T. 2014a. 'A device for being able to book P\&L': The organizational embedding of the Gaussian copula. Social Studies of Science, 44(3): $418-440$.

MacKenzie, D., \& Spears, T. 2014b. 'The formula that killed Wall Street': The Gaussian copula and modelling practices in investment banking. Social Studies of Science, 44(3): 393-417.

Marsh \& McLennan. 2018. Climate resilience handbook London: Marsh \& McLennan Companies.

Marti, E., \& Gond, J.-P. 2018. When do theories become self-fulfilling? Exploring the boundary conditions of performativity. Academy of Management Review, 43(3): 487-508.

McGoey, L. 2012a. The logic of strategic ignorance. British Journal of Sociology, 63(3): 533-576.

McGoey, L. 2012b. Strategic unknowns: Towards a sociology of ignorance. Economy and Society, 41(1): 1-16.
Mechler, R., Bouwer, L. M., Linnerooth-Bayer, J., Hochrainer-Stigler, S., Aerts, J. C. J. H., Surminski, S., \& Williges, K. 2014. Managing unnatural disaster risk from climate extremes. Nature Climate Change, 4(4): 235-237.

Milly, P. C. D., Betancourt, J., Falkenmark, M., Hirsch, R. M., Kundzewicz, Z. W., Lettenmaier, D. P., \& Stouffer, R. J. 2008. Stationarity is dead: Whither water management? Science, 319(5863): 573-574.

Monbiot, G. 2018. The UK government wants to put a price on nature - but that will destroy it. The Guardian. May 15.

Muir-Wood, R. 2016. The cure for catastrophe: How we can stop manufacturing natural disasters. New York: Basic Books.

Murphy, A. H. 1973. A new vector partition of the probability score. Journal of Applied Meteorology, 12(4): 595-600.

Pielke Jr., R. A., Gratz, J., Landsea, C. W., Collins, D., Saunders, M. A., \& Musulin, R. 2008. Normalized hurricane damage in the United States: 1900-2005. Natural Hazards Review, 9(1): 29-42.

Pielke Jr., R. A., Landsea, C. W., Musulin, R. T., \& Downton, M. 1999. Evaluation of catastrophe models using a normalized historical record. Journal of Insurance Regulation, 18(2): 177.

Polacek, A. 2018. Catastrophe bonds: A primer and retrospective. Chicago Fed Letter, 405: 1-7.

Popper, N. 2015. Success metrics questioned in school program funded by Goldman. New York Times. November 3.

Porter, M. E., \& Kramer, M. R. 2011. Creating shared value. Harvard Business Review, 89(1/2): 62-77.

Prahalad, C. K. 2006. The fortune at the bottom of the pyramid. Upper Saddle River, NJ: Pearson Prentice Hall.

Proctor, R. N. 2008. Agnotology: A missing term to describe the cultural production of ignorance (and its study). In R. N. Proctor, \& L. Schiebinger (Eds.), Agnotology: The making and unmaking of ignorance: $1-33$. Stanford: Stanford University Press.

Rescher, N. 2009. Ignorance: On the wider implications of deficient knowledge. Pittsburgh: University of Pittsburgh Press.

Risk Management Solutions. 2008. RMS ${ }^{\circledR}$ U.S. Hurricane model: RiskLink 8.0.1a.

Risk Management Solutions. 2013. North Atlantic Hurricane Model RMS® RiskLink 13.0 (Build 1509).

Risky Business Project. 2016. From risk to return: Investing in a clean energy economy/ https://riskybusiness. org/site/assets/uploads/sites/5/2016/10/RiskyBusiness_ 
FromRiskToReturn.pdf. Accessed November 29, 2019.

Ruggeri, A. 2017. 'Resilience bonds': A secret weapon against catastrophe. https://www.bbc.com/future/ article/20170515-resilience-bonds-a-secret-weaponagainst-catastrophe. Accessed November 29, 2019.

Sandel, M. J. 2013. What money can't buy: The moral limits of markets. New York: Farrar, Straus and Giroux.

Scism, L., \& Das, A. 2016. The insurance industry has been turned upside down by catastrophe bonds. Wall Street Journal. August 7.

Smithson, M. J. 2008. Social theories of ignorance. In R. N. Proctor, \& L. Schiebinger (Eds.), Agnotology: The making and unmaking of ignorance: 209-229. Stanford: Stanford University Press.

Standard \& Poor. 2013. Rating Natural Peril Catastrophe Bonds: Methodology And Assumptions. New York: Standard \& Poor's Financial Services, LLC.

Stovin-Bradford, R. 2015. Storm clouds gather around becalmed catastrophe bonds. Financial Times. October 31.

Sullivan, S., \& Hannis, M. 2017. "Mathematics maybe, but not money" on balance sheets, numbers and nature in ecological accounting. Accounting, Auditing $\&$ Accountability Journal, 30(7): 1459-1480.

Suri, T. 2017. Mobile money. Annual Review of Economics, 9: 497-520.

Surminski, S., Bouwer, L. M., \& Linnerooth-Bayer, J. 2016. How insurance can support climate resilience. Nature Climate Change, 6(4): 333-334.

Temple, J. 2017. Our hurricane risk models are dangerously out of date. MIT Technology Review, https://www. technologyreview.com/s/608800/our-hurricane-riskmodels-are-dangerously-out-of-date/. Accessed November 29, 2019.

Turco, M., Rosa-Cánovas, J. J., Bedia, J., Jerez, S., Montávez, J. P., Llasat, M. C., \& Provenzale, A. 2018. Exacerbated fires in Mediterranean Europe due to anthropogenic warming projected with non-stationary climate-fire models. Nature Communications, 9(1): 3821.

UN Conference on Trade and Development. 2014. World investment report 2014: Investing in the SDGs: An action plan. Geneva, Switzerland: UNCTAD.

UN Office for Disaster Risk Reduction. 2015. Disaster risk reduction and resilience in the 2030 agenda for sustainable development. New York: UNDRR.

UNEP. 2013. Insuring climate resilience. Geneva, Switzerland: United Nations Environment Programme - Finance Initiative.

UNEP FI. 2018. UNEP FI working with 16 global insurers to better understand risk \& implement TCFD recommendations. https://www.unepfi.org/news/industries/insurance/unep-fi-working-with-16-globalinsurers-to-better-understand-risk-implement-tcfdrecommendations/. Accessed November 29, 2019.

UPI. 2012. Cuomo: 'Extreme weather' needs new reality. UPI. https:/www.upi.com/Top_News/US/2012/10/30/CuomoExtreme-weather-needs-new-reality/46541351634041/. Accessed November 29, 2019.

Vinokurova, N. 2012. The 2008 mortgage crisis as a failure of analogical reasoning. New York: New York University, Graduate School of Business Administration.

Warner, M. E. 2013. Private finance for public goods: Social impact bonds. Journal of Economic Policy Reform, 16(4): 303-319.

Weinkle, J., \& Pielke Jr., R. 2017. The truthiness about hurricane catastrophe models. Science, Technology, \& Human Values, 42(4): 547-576.

Wilks, D. S. 2006. Statistical methods in the atmospheric sciences (2nd ed.). Oxford: Academic Press.

Willis Capital Markets \& Advisory. 2015. ILS glossary. New York: Willis.

Winkler, R. L. 1994. Evaluating probabilities: Asymmetric scoring rules. Management Science, 40(11): 1395-1405.

Winkler, R. L. 1996. Scoring rules and the evaluation of probabilities. Test, 5(1): 1-60.

World Economic Forum. 2019. The global risks report 2018 (14th ed.). Geneva, Switzerland: WEF.

Yunus, M. 1999. Banker to the poor: Micro-lending and the battle against world poverty. New York, NY: PublicAffairs.

Zelizer, V. A. 1979. Morals and markets: The development of life insurance in the United States. New York, NY: Columbia University Press.

Zuckerman, E. W. 2010. What if we had been in charge? The sociologist as builder of rational institutions. In M. Lounsbury, \& P. M. Hirsch (Eds.), Markets on trial: The economic sociology of the U.S. financial crisis, vol. 30B: 359-378. Bingham, UK: Emerald.

\section{M}

Dror Etzion (dror.etzion@mcgill.ca) is an associate professor of strategy and organizations at the Desautels Faculty of Management and an associate member of the McGill School of the Environment. He received his doctorate from IESE Business School. His current research program focuses on "grand challenges": the unyielding, intractable problems that characterize the Anthropocene.

Emmanuel Kypraios (emmanuel.kypraios@mu.ie) is a lecturer of management at the School of Business, Maynooth University. He received his $\mathrm{PhD}$ in management 
at the Università della Svizzera italiana/University of Lugano, Switzerland. His research focuses on how social classification systems of worth (e.g., status, rankings, ratings, and categorical affiliation) support rational decisionmaking in both traditional and dynamic markets. Before joining academia, he spent 13 years in the financial markets as senior trader and broker of equity derivatives.

Bernard Forgues (forgues@em-lyon.com) is a professor of organization theory and head of STORM Research Center at EMLYON Business School, France. He received his doctorate from Paris-Dauphine University. In his current research, he primarily explores how materiality affects and is affected by organizational practices, market categories, technologies, and field dynamics. His research has appeared in the AMJ, Org Science, Org Studies, and other journals. He currently serves as a senior editor for Organization Studies and as vice-chair for EGOS.

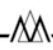

